\title{
Day-ahead stochastic scheduling of integrated multi-energy system for flexibility synergy and uncertainty balancing
}

Turk, Ana; Wu, Qiuwei; Zhang, Menglin; Østergaard, Jacob

\author{
Published in: \\ Energy
}

Link to article, DOI:

10.1016/j.energy.2020.117130

Publication date:

2020

Document Version

Early version, also known as pre-print

Link back to DTU Orbit

Citation (APA):

Turk, A., Wu, Q., Zhang, M., \& Østergaard, J. (2020). Day-ahead stochastic scheduling of integrated multienergy system for flexibility synergy and uncertainty balancing. Energy, 196, [117130].

https://doi.org/10.1016/j.energy.2020.117130

\section{General rights}

Copyright and moral rights for the publications made accessible in the public portal are retained by the authors and/or other copyright owners and it is a condition of accessing publications that users recognise and abide by the legal requirements associated with these rights.

- Users may download and print one copy of any publication from the public portal for the purpose of private study or research.

- You may not further distribute the material or use it for any profit-making activity or commercial gain

- You may freely distribute the URL identifying the publication in the public portal 


\title{
Day-ahead stochastic scheduling of integrated multi-energy system for flexibility synergy and uncertainty balancing
}

Ana Turk ${ }^{\mathrm{a}}$, Qiuwei $\mathrm{Wu}^{\mathrm{a},{ }^{*}, \text { Menglin Zhang }}{ }^{\mathrm{a}}$, Jacob Østergaard ${ }^{\mathrm{a}}$

a Center for Electric Power and Energy (CEE), Department of Electrical Engineering, Technical University of Denmark (DTU), 2800 Kgs. Lyngby, Denmark

\begin{abstract}
Secure operation of the power system is challenged by the high level of uncertainty and fluctuation introduced by renewable energy sources. More flexibility is needed to cope with the uncertainty and improve the utilization of renewable energy. A prominent solution to provide flexibility, and simultaneously increase the efficiency of the system, is the integration of different energy sectors. This paper proposes a two-stage stochastic scheduling scheme of an integrated multi-energy system, which considers the wind power uncertainty and the synergy of different energy sectors to achieve the optimal economic operation of the whole system with minimum curtailment of wind power. In the first stage, energy and reserve scheduling of generating units is performed, while accommodation of wind power production is realized through reserves in the second stage. In the proposed scheme, the electric power system, natural gas system, and district heating system are coordinated to achieve more flexibility, both in the day-ahead and real-time stage. The stochasticity of the wind power uncertainty is represented by realistic scenarios with corresponding probabilities, which are obtained from a scenario generation algorithm based on historical observations taking into account the temporal correlation of wind power. The simulation results on a smallscale test system show that both, the economic efficiency and wind power utilization, have been improved with more flexibility and more reliable scenario set. It is shown, that the total system cost is reduced and reserves are optimized.
\end{abstract}

\section{Keywords:}

Integrated multi-energy system, temporal-correlated scenario set, two-stage stochastic programming, wind power uncertainty

Notation

\begin{tabular}{lll} 
Symbol & Description & Unit \\
\hline Sets & & \\
$\Lambda^{E P S / D H S / N G S}$ & Set of nodes in EPS/DHS/NGS & \\
$\Omega_{n}^{E D / W T}$ & Set of electricity demands/wind turbines at node $n$ & \\
$\Omega_{n}^{H L / H S / C H P}$ & Set of heat demands//heat storages/CHP at node $n$ & \\
$\Omega_{n}^{G S / G D / G C / P 2 G / S T}$ & Set of gas sources/gas demands/GC/P2G/gas storages at node $n$ & \\
$\Theta$ & Set of scenarios & \\
$T$ & Set of hours & $\mathrm{W} / \mathrm{m}^{\circ} \mathrm{C}$ \\
Constants & & \\
$\lambda_{m n, t}$ & Thermal conductivity of pipe m-n & \\
$\lambda_{g}^{\mathrm{GC}}$ & Operational energy consumption coefficient of GC $g$ & \\
$\eta^{\mathrm{GC}}$ & Compression efficiency of GC $g$ & \\
$\eta_{j}^{\mathrm{e}}, \eta_{j}^{h}$ & Generating electrical and thermal efficiency of CHP unit $j$ & \\
$\eta_{k}^{\mathrm{P} 2 \mathrm{G}}$ & The energy conversion efficiency of at P2G unit \\
$\tau_{m n, t}^{\text {in/out,min/max }}$ & Minimum/maximum water temperature of inlet/outlet of pipe $m-n$ & ${ }^{\circ} \mathrm{C}$
\end{tabular}

*Corresponding author: Q. Wu (email: qw@elektro.dtu.dk). 


\begin{tabular}{|c|c|c|}
\hline$\tau_{m n, t}^{a}$ & Ambient temperature & ${ }^{\circ} \mathrm{C}$ \\
\hline$B_{n m}$ & Susceptance of transmission line $n-m$ & p.u. \\
\hline$c$ & Specific heat capacity of water & $\mathrm{J} / \mathrm{kg}^{\circ} \mathrm{C}$ \\
\hline$c_{k}, C R$ & Specific heat ratio for natural gas and compression ratio & \\
\hline$C_{j}^{\mathrm{CHP}, \mathrm{P}}$ & Marginal cost of power of CHP & $\$ / \mathrm{MWh}$ \\
\hline$C_{g}^{\mathrm{GS}}, C_{k}^{P 2 G}$ & Marginal cost of gas supply: gas source and $\mathrm{P} 2 \mathrm{G}$ & $\$ / \mathrm{MWh}$ \\
\hline$C_{j}^{\mathrm{CHP}, \mathrm{P}, \mathrm{UR}}$ & Marginal cost of upward reserves of the CHP unit $j$ & $\$ / \mathrm{MWh}$ \\
\hline$C_{j}^{\mathrm{CHP}, \mathrm{P}, \mathrm{DR}}$ & Marginal cost of downward reserves of the CHP unit $j$ & $\$ / \mathrm{MWh}$ \\
\hline$C_{j}^{C H P, H}$ & Marginal cost of heat supply from CHP & $\$ / \mathrm{MWh}$ \\
\hline$C_{h}^{\mathrm{HST}, \text { out }}, C_{h}^{\mathrm{HST}, \text { in }}$ & Marginal cost of heat input/output to/from heat storage & $\$ / \mathrm{MWh}$ \\
\hline$C_{s}^{\mathrm{GST}, \text { in }}, C_{s}^{\mathrm{GST}, \text { out }}$ & Marginal cost of gas input/output to/from gas storage & $\$ / \mathrm{MWh}$ \\
\hline$C_{k}^{\mathrm{P} 2 \mathrm{G}, \mathrm{DR}}$ & Marginal cost of downward reserves of $\mathrm{P} 2 \mathrm{G}$ unit $k$ & $\$ / \mathrm{MWh}$ \\
\hline$C_{k}^{\mathrm{P} 2 \mathrm{G}, \mathrm{UR}}$ & Marginal cost of upward reserves of $\mathrm{P} 2 \mathrm{G}$ unit $k$ & $\$ / \mathrm{MWh}$ \\
\hline$C_{e}^{V O L L}$ & Value of lost load & $\$ / \mathrm{MWh}$ \\
\hline$C_{k}^{\text {spill }}$ & Penalty for wind spillage & $\$ / \mathrm{MWh}$ \\
\hline$C_{t}$ & Total expected operational cost of the integrated system & $\$ / \mathrm{h}$ \\
\hline$D_{d, t}^{\mathrm{GD}}, D_{e, t}^{E D}$ & Gas demand of NGS and electric demand of EPS & MW \\
\hline$E^{\mathrm{GC}}$ & GC parasitic efficiency & \\
\hline$H_{j}^{C H P, \min / \max }$ & Max/min heat supply from CHP unit $j$ & MW \\
\hline$H_{l, t}^{H L}$ & Heat demand & MW \\
\hline$H_{h}^{H S, \text { in } / \text { out }, \min / \max }$ & Minimum/maximum heat input/output capacity of heat storage $h$ & MW \\
\hline$H S_{h}^{\min / \max }$ & Max/min heat reserve in heat storage $\mathrm{h}$ & MWh \\
\hline$K^{\mathrm{GC}}$ & Constant of GC & \\
\hline$L H V$ & Lower heating value & $\mathrm{MJ} / \mathrm{m}^{3}$ \\
\hline$L_{m n}$ & Length of district heating pipe $m-n$ & $\mathrm{~m}$ \\
\hline$m_{m n, t}^{\max / \min }$ & $\mathrm{Max} / \mathrm{min}$ water flow rate in pipe $\mathrm{m}-\mathrm{n}$ & $\mathrm{kg} / \mathrm{s}$ \\
\hline$\left(p_{n, t}^{2}\right)^{\min / \max }$ & Minimum/maximum operating limits for gas pressure of node $n$ & $\mathrm{MPa}^{2}$ \\
\hline$P_{j, t}^{C H P, \min / \max }$ & Min/max power supply from CHP unit $j$ & MW \\
\hline$P_{m n}^{\max }$ & Maximum transmission capacity of line m-n & MW \\
\hline$Q_{g}^{\mathrm{GSS} \min / \max }$ & Minimum/maximum gas supply from gas source $g$ & MW \\
\hline$Q_{k}^{\mathrm{P} 2 \mathrm{G}, \min / \max }$ & Minimum and maximum level from $\mathrm{P} 2 \mathrm{G}$ unit $k$ & MW \\
\hline$Q_{s}^{\mathrm{ST}, \mathrm{in} / \mathrm{out}, \max }$ & Gas input/output capacity of gas storage $s$ & MW \\
\hline$R_{j, t}^{\mathrm{CHP}, \mathrm{U}, \max }, R_{j, t}^{\mathrm{CHP}, \mathrm{D}, \max }$ & Maximum reserve capacity of CHP unit $\mathrm{j}$ & MW \\
\hline$R_{k, t}^{P 2 G, U, \max }, R_{k, t}^{P 2 G, D, \max }$ & Maximum reserve capacity of $\mathrm{P} 2 \mathrm{G}$ unit $\mathrm{k}$ & MW \\
\hline$R L D_{j}^{\mathrm{CHP}}$ & Downward ramping rate limit of CHP unit $j$ & $\mathrm{MW} / \mathrm{h}$ \\
\hline$R L U_{j}^{\mathrm{CHP}}$ & Upward ramping rate limit of CHP unit $j$ & $\mathrm{MW} / \mathrm{h}$ \\
\hline$S_{n m}^{\max }$ & Transmission capacity of gas pipeline $n-m$ & MW \\
\hline$S T_{s}^{\min / \max }$ & Minimum/maximum gas stock in gas storage $s$ & $\mathrm{MWh}$ \\
\hline
\end{tabular}




\begin{tabular}{|c|c|c|}
\hline$T_{s}, Z_{\mathrm{a}}$ & Suction temperature of GC and average compressibility factor & ${ }^{\circ} \mathrm{R},-$ \\
\hline$W_{f, t}^{\max }$ & Nominal output power of wind unit $f$ & MW \\
\hline$W_{f, \omega, t}^{R T}$ & Wind power output realization in RT stage & MW \\
\hline$Z_{n m}$ & Resistance coefficient of the pipeline & $\mathrm{kPa}^{2} /(\mathrm{MW})^{2}$ \\
\hline \multicolumn{3}{|l|}{ Variables } \\
\hline$\delta_{n, t}$ & Phase angle of bus $n$ & $\mathrm{rad}$ \\
\hline$\tau_{m n, t}^{\text {in }}$ & Temperature of inlet to node $n$ of pipe m-n & ${ }^{\circ} \mathrm{C}$ \\
\hline$\tau_{m n, t}^{\text {out }}$ & Temperature of outlet of node m of pipe m-n & ${ }^{\circ} \mathrm{C}$ \\
\hline$D_{j, t}^{\mathrm{CHP}}, D_{k, t}^{P 2 G}$ & Gas consumption in CHP unit $j$ and power demand in $\mathrm{P} 2 \mathrm{G}$ unit $k$ & MW \\
\hline$D_{g, t}^{\mathrm{GC}}$ & Gas consumption in $\mathrm{GC} g$ & MW \\
\hline$D_{e, \omega, t}^{\mathrm{ED}, \text { shed }}$ & Load shedding in scenario $w$ & MW \\
\hline$G_{n m, t}$ & Gas flow rate in pipeline $n-m$ & $\mathrm{~m}^{3} / \mathrm{h}$ \\
\hline$H_{j, t}^{C H P}$ & Heat supply from CHP unit $\mathrm{j}$ & MW \\
\hline$H_{h, t}^{H S, i n}$ & Heat output of heat storage $\mathrm{h}$ to heat network, & MW \\
\hline$H_{h, t}^{H S, \text { out }}$ & Heat output of heat network to heat storage $\mathrm{h}$ & MW \\
\hline$H S_{h, t}$ & Heat stocks in heat storage $\mathrm{h}$ & $\mathrm{MWh}$ \\
\hline$m_{m n, t}$, & Water flow rate in pipe $\mathrm{m}-\mathrm{n}$ & $\mathrm{kg} / \mathrm{s}$ \\
\hline$p_{n, t}^{2}$ & Gas pressure of node $n$ & $\mathrm{MPa}^{2}$ \\
\hline$P_{j, t}^{\mathrm{CHP}}$ & Power supply from CHP unit $j$ & MW \\
\hline$Q_{g, t}^{\mathrm{GS}}$, & Gas supply from gas source $g$ & MW \\
\hline$Q_{k, t}^{\mathrm{P} G}$ & Gas supply from $\mathrm{P} 2 \mathrm{G}$ unit $k$ & MW \\
\hline$Q_{s, t}^{\mathrm{ST} \text {,in/out }}$ & Gas input/output of gas storage $s$ & MW \\
\hline$R_{k, \omega, t}^{P 2 G, U}, R_{k, \omega, t}^{P 2 G, D}$ & Upward and downward reserves of $\mathrm{P} 2 \mathrm{G}$ unit $k$ in scenario $w$ & MW \\
\hline$R_{j, \omega, t}^{\mathrm{CHP}, \mathrm{U}}, R_{j, \omega, t}^{\mathrm{CHP}, \mathrm{D}}$ & Upward and downward reserves of CHP unit $j$ in scenario $w$ & MW \\
\hline$S_{n m, t}, S_{g, t}^{\mathrm{GC}}$ & Gas flow rate: of gas pipeline $n-m$, through gas compressor & MW \\
\hline$S T_{s, t}$ & Gas stocks in gas storage $s$ & MWh \\
\hline$W_{f, t}^{D A}, W_{f, \omega, t}^{\text {spill }}$ & Scheduled power output and spillage of wind unit $f$ & MW \\
\hline$x_{s, t}^{\mathrm{ST}, \mathrm{in}}$ & Binary variable, 1 if gas storage is storing gas, otherwise 0 & \\
\hline$x_{s, t}^{\mathrm{ST}, \text { out }}$ & Binary variable, 1 if gas is withdrawn from gas storage otherwise 0 & \\
\hline$x_{h, t}^{\mathrm{HS}, \mathrm{in}}$ & Binary variable, 1 if the heat is withdrawn from the heat storage $h$, & therwise 0 \\
\hline$x_{h, t}^{\mathrm{HS}, \text { out }}$ & Binary variable, 1 if the heat storage $h$ is storing heat, otherwise 0 & \\
\hline
\end{tabular}

\section{Introduction}

Nowadays power systems face a major change as an increasing amount of the electricity production stems from renewable energy sources (RES) while conventional generation is gradually phased out. The uncertainty and fluctuation of non-dispatchable RES such as wind and solar, which are subject to prevailing weather conditions, particularly challenges the task of balancing demand and generation. As the amount of 
power from non-dispatchable RES increases - in Denmark, for instance, $43.4 \%$ of the electricity consumption in 2017 was covered solely by wind power [1] - more flexibility needs to be provided by other sources. In order to realize the long-term goal of RES based energy systems operating in a secure, reliable and economic manner, new solutions for providing flexibility have to be developed. New technologies, such as power-to-gas (P2G) can enable bidirectional energy conversion [2], which provides the opportunity to investigate possible synergies between the electricity, heat and gas systems. This is one of the primary objectives of the International Conference on Smart Energy Systems and $4^{\text {th }}$ Generation District Heating, Electrification, Electrofuels and Energy Efficiency. The district heating system is gaining a lot of attention in the future smart energy systems. The current research overview within the district heating operation including the 4th Generation District Heating and balancing capability of district heating system to accommodate RES was presented in [3].

Optimal power flow (OPF) has been the main tool to operate the electric power system (EPS) as reliable and as economical as possible [4] but it neglects the potential links to other sectors. Cogeneration and conversion units allow coupling the EPS and the heating system and extensive research has been conducted regarding the coordination and linking of the EPS and the district heating system (DHS). The development of the DHS and its integration into the smart energy systems was reviewed in [5]. The future DHS is to operate at low-temperature while having lower network losses and the ability to accommodate fluctuating RES. Further on, dynamic modeling approach was used in [6] for coupled EPS and DHS in order to obtain smart energy system incorporating RES and lowering the temperature of DHS. Coordination and optimal dispatch of integrated DHS and EPS including a wind farm for an urban area was performed in [7]. A decomposed coordination algorithm was used to solve the non-linear problem in order to obtain a suboptimal solution and it is shown that coordinated operation reduces wind curtailment, operational costs, and energy losses. In [8], an integrated method was proposed for the combined analysis of the EPS and DHS in order to reduce the number of iterations compared to the decomposed analysis. Besides the coordination of the EPS and DHS, a considerable amount of literature can be found regarding the coordination of the natural gas system (NGS) and the EPS. An algorithm was proposed in [9] to analyze the interactions of different sectors of the multi-energy system (MES). The congestion problem was studied in the MES to utilize the interaction of multi-energy vectors to resolve the congestion [10]. Modeling and optimal operation of NGS and EPS in order to maximize social welfare are presented in [11]. A novel integrated demand response was formulated in [12] to enhance conventional demand response for the EPS and NGS. It is shown that the coupling of different energy sectors enables consumers to participate in demand response by switching the energy source or shifting their demand. Bi-directional energy conversion and regulation ability of P2G to accommodate RES are presented in [2] and [13]-[15]. It is shown that P2G is a promising solution for balancing fluctuation and uncertainty of RES, which, due to its fast response, can also provide peak regulating capacity.

The previously mentioned articles only focus on the coupling of two different energy sectors but already demonstrate the potential of $\mathrm{P} 2 \mathrm{G}$ and combined heat and power (CHP) to provide the flexibility required by the future RES based system. An approach for designing an integrated and coordinated multi-energy system combining EPS, DHS and NGS considering the linking components as well as network constraints of each system is presented in [16]. Planning strategies and coordination of the individual energy sectors were derived that could increase the flexibility and efficiency of the Danish energy system. Integration and coordination of multiple energy sectors in order to achieve sustainable and efficient energy system is often referred as smart energy system and the review on smart energy systems was given in [17]. It is one of the most significant challenges to develop a multi-disciplinary integrated energy management system (IEMS). 
The idea and framework of the IEMS was developed in [18] for the first time over the world. It is the first IEMS developed over the world and is considered as the brain of the MES. This IEMS has been implemented in a number of sites in China and has significantly improved the energy efficiency and reduced the energy cost.

In [19], the coordinated operation of the multi-energy system based on a detailed model was described. In [20], it was shown that the deterministic model for day-ahead (DA) scheduling, as used in [19], fails to capture the uncertainties in the energy system leading to a mismatch between DA scheduling and real-time (RT) operation. They, therefore, proposed a two-stage stochastic programming approach taking into account wind power uncertainties to improve the model in [19]. The aim is to minimize the total expected operational cost of the EPS, DHS and NGS while assuming constant water temperature and gas pressure. That scheduling of the multi-energy system relying on multi-stage stochastic programming rather than using a deterministic approach leads to lower operational costs was also shown in [21].

Stochastic optimization has gained a lot of attention in the field of optimization under uncertainty and stochastic DA scheduling has been mostly used in the field of EPS [22]-[24]. In [25], a decentralized algorithm was used for DA scheduling resulting in lower computational time compared to the centralized algorithm. In the algorithm, the individual objectives of load aggregators and generators were jointly optimized, while the physical constraints of the power system were respected.

Stochastic optimization requires a large number of scenarios to be included in the optimization problem to obtain a realistic representation of all possible future states with their corresponding probability of occurrence, which makes it infeasible for real-time operation [26]. Existing stochastic-scenario based programming approaches differentiate substantially in terms of the method used for scenario generation (SG). In some cases, scenario reduction (SR) methods were applied prior to performing optimization in order to reduce the computational burden.

Table 1 lists some of the existing SG and SR methods along with their applications in energy systems and optimization models.

Table 1 Literature review of SG and SR methods, its applications and optimization model used in the studies

\begin{tabular}{|c|c|c|c|c|c|c|c|}
\hline Ref & $\mathrm{SG}$ & SG Method & SR & SR Method & Application & Uncertainty & Model \\
\hline [27] & $\nabla$ & ARMA & $\nabla$ & $\begin{array}{l}\text { SR algorithm } \\
\text { and ST }\end{array}$ & $\begin{array}{l}\text { Optimal operation of } \\
\text { energy efficient buildings }\end{array}$ & $\begin{array}{l}\text { Solar power, heat, and } \\
\text { electric load }\end{array}$ & MILP \\
\hline$[28]$ & $\nabla$ & $\begin{array}{l}\text { Rayleigh PDF of wind } \\
\text { speed and wind } \\
\text { turbine power curve }\end{array}$ & 凶 & 凶 & $\begin{array}{c}\text { Multi-period OPF } \\
\text { considering HVDC-linked } \\
\text { wind farms }\end{array}$ & Wind power & NLP \\
\hline [29] & $\nabla$ & $\begin{array}{l}\text { Rayleigh PDF of wind } \\
\text { speed, clustering } \\
\text { technique for load } \\
\text { modeling }\end{array}$ & $\nabla$ & $\begin{array}{l}\text { Aggregation of } \\
\text { similar states }\end{array}$ & $\begin{array}{l}\text { Planning technique for } \\
\text { distribution system }\end{array}$ & $\begin{array}{l}\text { Combined uncorrelated } \\
\text { generation-load model }\end{array}$ & MINLP \\
\hline$[30]$ & $\nabla$ & $\begin{array}{l}\text { Weibull PDF of wind } \\
\text { speed and Monte } \\
\text { Carlo }\end{array}$ & 凶 & 凶 & $\begin{array}{l}\text { Wind generation cost } \\
\text { model }\end{array}$ & Wind power & NLP \\
\hline [31] & $\nabla$ & $\begin{array}{l}\text { Weibull PDF for wind } \\
\text { speed, normal PDF } \\
\text { and Monte Carlo } \\
\text { simulation [32] }\end{array}$ & $\nabla$ & $\begin{array}{l}\text { Backward SR } \\
\text { algorithm }\end{array}$ & $\begin{array}{l}\text { Coordinated scheduling of } \\
\mathrm{CHP}, \mathrm{WT}, \mathrm{PV} \text { and thermal } \\
\text { units in a MG }\end{array}$ & $\begin{array}{l}\text { Wind speed, solar } \\
\text { irradiation, electricity } \\
\text { market price }\end{array}$ & $\begin{array}{l}\text { MINLP and } \\
\text { proposed method } \\
\text { based on MPSO }\end{array}$ \\
\hline [33] & $\nabla$ & $\begin{array}{c}\text { Roulette Mechanism } \\
\text { based on normal PDF } \\
\text { of random variables } \\
{[32]}\end{array}$ & $\nabla$ & $\begin{array}{l}\text { Backward SR } \\
\text { algorithm }\end{array}$ & $\begin{array}{l}\text { Planning location and } \\
\text { operation of fuel cell } \\
\text { power plant in a system } \\
\text { with CHP }\end{array}$ & $\begin{array}{l}\text { Electric and heat load } \\
\text { forecast, gas pressures } \\
\text { and temperatures for } \\
\text { fuel call plant }\end{array}$ & $\begin{array}{l}\text { MINLP;modified } \\
\text { Firefly } \\
\text { Algorithm and } \\
\text { Pareto method }\end{array}$ \\
\hline [32] & $\nabla$ & Monte Carlo & $\nabla$ & $\begin{array}{l}\text { Backward SR } \\
\text { algorithm and } \\
\text { ST }\end{array}$ & $\begin{array}{l}\text { Long-term security- } \\
\text { constrained unit } \\
\text { commitment }\end{array}$ & $\begin{array}{l}\text { Outages of generating } \\
\text { units and lines, load } \\
\text { forecasting errors }\end{array}$ & $\begin{array}{c}\text { MIP; } \\
\text { Decomposition } \\
\text { and Lagrangian } \\
\text { relaxation }\end{array}$ \\
\hline
\end{tabular}




\begin{tabular}{|c|c|c|c|c|c|c|c|}
\hline [34] & $\nabla$ & $\begin{array}{l}\text { ARMA and wind } \\
\text { turbine power curve, } \\
\text { SARIMA used for } \\
\text { market prices }\end{array}$ & $\nabla$ & $\begin{array}{l}\text { Fast-forward } \\
\text { algorithm }\end{array}$ & $\begin{array}{l}\text { Two-stage DA scheduling } \\
\text { of integrated multi-energy } \\
\text { systems neglecting the } \\
\text { network }\end{array}$ & $\begin{array}{l}\text { Wind power and DA } \\
\text { market price based on } \\
\text { historical data }\end{array}$ & MISOCP \\
\hline [35] & $\nabla$ & ARIMA and heuristic & $\nabla$ & $\begin{array}{l}\text { Traditional and } \\
\text { proposed } \\
\text { forward SR } \\
\text { algorithm }\end{array}$ & $\begin{array}{l}\text { Uncertainty in trading } \\
\text { problems in electricity } \\
\text { markets }\end{array}$ & Pool prices & LP \\
\hline [36] & $\nabla$ & $\begin{array}{l}\text { Based on historical } \\
\text { data, including the } \\
\text { seasonal effects }\end{array}$ & $\nabla$ & $\begin{array}{l}\text { Fast-forward } \\
\text { SR algorithm }\end{array}$ & $\begin{array}{l}\text { Development of three } \\
\text { complementary methods } \\
\text { for SG for stochastic wind } \\
\text { power }\end{array}$ & $\begin{array}{l}\text { Wind power; wind } \\
\text { power forecast error }\end{array}$ & LP \\
\hline [37] & $\nabla$ & $\begin{array}{l}\text { Empirical CDF for } \\
\text { wind power forecast } \\
\text { error and Gaussian } \\
\text { random vector }\end{array}$ & $\nabla$ & $\begin{array}{l}\text { Backward SR } \\
\text { algorithm }\end{array}$ & $\begin{array}{l}\text { Wind power; Wind power } \\
\text { forecast error }\end{array}$ & $\begin{array}{l}\text { SG for wind power } \\
\text { production based on } \\
\text { historical observations }\end{array}$ & $\begin{array}{l}\text { Not applied to } \\
\text { power system }\end{array}$ \\
\hline
\end{tabular}

Based on the work in [36]-[38], and the literature review, it can be concluded that, significant error in the results can appear by using the wind speed to generate scenarios for wind power, due to inaccuracies in the wind to power conversion. Moreover, the forecast error of wind power is dynamic and the temporal correlation due to wind variability cannot be neglected. Hence, approaches like autoregressive moving average models and Monte Carlo cannot be used. Moreover, the probability density function (PDF) of wind speed cannot be assumed to follow a theoretical distribution due to the fluctuating nature and variability of the wind speed. In this work scenario generation is therefore based on the empirical cumulative distribution function of measured historical data which is considered more suitable. The proposed SG method has not been applied to the integrated energy system (IES) so far. Hence, the suitability of the application of the SG method to IES is validated.

Though great efforts have been done for the IES day-ahead scheduling, there are still many aspects to be improved. This paper mainly focuses on two aspects: one is how to provide more flexibility to balance the wind power uncertainty through the synergy of different energy sectors in IES, the other is to provide an advanced scenario set of wind power for the IES to properly represent the flexibility requirement and make a more reliable and economical decision. The main contributions are summarized as follows:

- This work proposes a two-stage stochastic scheduling scheme for the integrated multi-energy system considering wind power uncertainty and synergy of different energy sectors which aims to reduce the system operation cost and improve wind power utilization with improved flexibility.

- The coupling between different energy sectors and the linkage between day-ahead and real-time are both formulated in detail. Besides, the heat storage and gas storage are utilized to strengthen the synergy of different energy sectors in order to provide more flexibility.

- An advanced scenario set of wind power is generated as the input of the stochastic programming considering the temporal correlation and scenario reduction.

The remainder of the paper is organized as follows. Section 2 formulates the day-ahead stochastic scheduling model of the IES. Section 3 details the procedure of generating the advanced scenario set. The effectiveness of the proposed method by case studies is shown in Section 4, followed by the conclusions.

\section{Day-ahead stochastic scheduling model of IES}

In this section, the DA stochastic scheduling model of the IES is formulated, considering the wind power uncertainty and synergy of different energy sectors simultaneously. The objective is to minimize the operational cost of the whole system while satisfying all security constraints. The formulated model is a two-stage stochastic program with the first stage representing the day-ahead operation and the second stage 
representing the real-time balancing. With such a model, the day-ahead decision will be robust for all the uncertainty realization in real-time.

The main difference between the proposed model and the existing models lies in the utilization of the coordinated flexibility to balance the wind power in two stages, and the heat storage, gas storage, and P2G are considered simultaneously. The $\mathrm{P} 2 \mathrm{G}$ unit has gained a lot of attention because it is a prominent solution for handling electricity under- and over-production. In Denmark, short term heat storage is integrated in all DHS. Hence, CHP can increase or decrease production in moments of high or low electricity demand respectively. In moments of higher heat production compared to heat demand, the heating is being stored in the heat storage. On the contrary, in moments of high heat demand, the heat is released from the heat storage [39]. Denmark has two gas storage units as well, which are able to cover around one third of the annual consumption of gas [40]. Therefore, the coordination of the electricity, heat, and gas system with integrated gas and heat storage units and P2G can further improve the flexibility and efficiency of the entire integrated system. Besides, the link between day-ahead operation and real-time balancing and the coupling between different energy sectors in real-time stage are formulated in detail for the whole system. The mixed integer non-linear problem of the IES is linearized in order to obtain the global optimum.

The proposed model includes four parts, the objective function, the first-stage constraints, the second stage constraints and the linkage constraints of different subsystems.

\subsection{Objective function}

The objective of the IES scheduling model is to minimize the total expected operational cost of the whole system in two stages as shown in Eq. (1). The first two parts represent the DA stage, while the last part considers the RT stage dependent on the realization of the wind power scenario. The first part includes the electricity and heat production cost from CHP and heat storage charge/discharge cost. Further on, gas supply cost, gas storage charge/discharge cost, and gas production cost of the $\mathrm{P} 2 \mathrm{G}$ unit are included in the second part. The RT second stage is divided based on the specific unit able to provide reserves and energy in the RT. Firstly, the cost of upward and downward reserves and heat energy regulation costs of CHP units are described. Secondly, the regulation cost of gas supply and the regulation cost for upward and downward reserves of P2G units are shown. The deployment cost of gas storage charge/discharge and the deployment cost of heat storage charge/discharge are shown in the third and fourth lines of the RT stage respectively. Lastly, the value of lost load (VLL), and the wind power spillage cost are included. In the RT stage, only the reserves and the energy difference between the RT and DA stage are taken into account. The wind uncertainties are represented through a number of scenarios for a period of 24 hours. Each scenario has a corresponding probability. 


$$
\begin{aligned}
C_{t}=\min & \sum_{t=1}^{n^{\mathrm{T}}}\left\{\sum_{j=1}^{n_{g}} C_{j}^{\mathrm{CHP}, \mathrm{P}} P_{j, t}^{\mathrm{CHP}, \mathrm{DA}}+\sum_{j=1}^{n^{\mathrm{CHP}}}\left(C_{j}^{\mathrm{CHP}, H} H_{j, t}^{\mathrm{CHP}, \mathrm{DA}}\right)+\sum_{h=1}^{n^{H S}}\left(C_{h}^{\mathrm{HST}, \mathrm{in}} H_{h, t}^{\mathrm{HS}, \mathrm{in}, \mathrm{DA}}+C_{h}^{\mathrm{HST}, \mathrm{out}} H_{h, t}^{\mathrm{HS}, \mathrm{ou}, \mathrm{DA}}\right)\right\} \\
& +\sum_{t=1}^{n^{T}}\left\{\sum_{g=1}^{n^{\mathrm{GS}}} C_{g}^{\mathrm{GS}} Q_{\mathrm{g}, t}^{\mathrm{GS}, \mathrm{DA}}+\sum_{s=1}^{n^{\mathrm{ST}}}\left(C_{s}^{\mathrm{GST}, \mathrm{in}} Q_{s, t}^{\mathrm{ST}, \mathrm{in}, \mathrm{DA}}+C_{s}^{\mathrm{GST}, \mathrm{out}} Q_{s, t}^{\mathrm{ST}, \mathrm{out}, \mathrm{DA}}\right)+\sum_{k=1}^{n^{P 2} G} C_{k}^{P 2 G} Q_{k, t}^{P 2 G, D A}\right\} \\
& +\sum_{\omega \in \Phi} \pi_{\omega} \sum_{t=1}^{n^{\mathrm{T}}}\left\{\sum_{j=1}^{n^{\mathrm{CHP}}}\left[C_{j}^{\mathrm{CHP}, \mathrm{P}, \mathrm{UR}} R_{j, \omega, t}^{\mathrm{CHP}, \mathrm{U}}-C_{j}^{\mathrm{CHP}, \mathrm{P}, \mathrm{DR}} R_{j, \omega, t}^{\mathrm{CHP}, \mathrm{D}}+C_{j}^{\mathrm{CHP}, \mathrm{H}}\left(H_{j, \omega, t}^{\mathrm{CHP}, \mathrm{RT}}-H_{j, t}^{\mathrm{CHP}, \mathrm{DA}}\right)\right]\right. \\
& +\sum_{g=1}^{n^{\mathrm{GS}}} C_{g}^{\mathrm{GS}}\left(Q_{g, \omega, t}^{\mathrm{GS}, \mathrm{RT}}-Q_{g, t}^{\mathrm{GS}, \mathrm{DA}}\right)+\sum_{k=1}^{n^{\mathrm{P} 2 \mathrm{G}}}\left[C_{k}^{\mathrm{P} 2 \mathrm{G}, \mathrm{UR}} R_{k, \omega, t}^{\mathrm{P} \mathrm{G}, \mathrm{U}}-C_{k}^{\mathrm{P} 2 \mathrm{G}, \mathrm{DR}} R_{k, \omega, t}^{\mathrm{P} 2 \mathrm{G}, \mathrm{D}}\right] \\
& +\sum_{s=1}^{n^{\mathrm{T}}}\left[C_{s}^{\mathrm{GST}, \mathrm{in}}\left(Q_{s, \omega, t}^{\mathrm{ST}, \mathrm{in}, \mathrm{RT}}-Q_{s, t}^{\mathrm{ST}, \mathrm{in}, \mathrm{DA}}\right)+C_{s}^{\mathrm{GST}, \mathrm{out}}\left(Q_{s, \omega, t}^{\mathrm{ST}, \mathrm{out}, \mathrm{RT}}-Q_{s, t}^{\mathrm{ST}, \mathrm{ou}, \mathrm{DA}}\right)\right] \\
& +\sum_{h=1}^{n^{\mathrm{HS}}}\left[C_{h}^{\mathrm{HST}, \mathrm{in}}\left(H_{h, \omega, t}^{\mathrm{HST}, \mathrm{in}, \mathrm{RT}}-H_{h, t}^{\mathrm{HST}, \mathrm{in}, \mathrm{DA}}\right)+C_{h}^{\mathrm{HST}, \mathrm{out}}\left(H_{h, \omega, t}^{\mathrm{HST}, \mathrm{ou}, \mathrm{RT}}-H_{h, t}^{\mathrm{HST}, \mathrm{ou}, \mathrm{DA}}\right)\right] \\
& \left.+\sum_{e=1}^{n^{\mathrm{ED}}} C_{e}^{V O L L} D_{e, \omega, t}^{\mathrm{ED}, \mathrm{shed}}+\sum_{k=1}^{n^{\mathrm{ED}}} C_{k}^{\text {spill }} W_{f, \omega, t}^{s p i l l}\right\}
\end{aligned}
$$

\subsection{First-stage constraints}

In this subsection, the first-stage constraints for the EPS, DHS and NGS are separately shown. The firststage constraints of the EPS include (1)-(8). Eq. (2) represents the nodal power balance between CHP units, wind farms, P2G stations, and electrical demand. Eqs. (3) and (4) limit the range of CHP units and wind farms respectively. Eq. (5) describes the transmission capacity of lines based on the DC power flow method. Eqs. (6) and (7) represent the upward and downward ramping rates of CHP units respectively. Eq. (8) describes the angle constraint of the reference bus.

$$
\begin{gathered}
\sum_{j \in \Omega_{n}^{\mathrm{CHP}}} P_{j, t}^{\mathrm{CHP}, \mathrm{DA}}+\sum_{f \in \Omega_{n}^{\mathrm{WT}}} W_{f, t}^{D A}-\sum_{k \in \Omega_{n}^{\mathrm{P} Z \mathrm{G}}} D_{k, t}^{\mathrm{P} 2 \mathrm{DA}}-\sum_{d \in \Omega_{n}^{\mathrm{ED}}} D_{d, t}^{\mathrm{ED}}=\sum_{m \in \Lambda^{E P S}} B_{n m}\left(\delta_{n, t}^{D A}-\delta_{m, t}^{D A}\right), \forall n \in \Lambda^{\mathrm{EPS}}, \forall t \in T \\
P_{j}^{\mathrm{CHP}, \min } \leq P_{j, t}^{\mathrm{CHP}, \mathrm{DA}} \leq P_{j}^{\mathrm{CHP}, \max }, \forall j \in \Omega^{\mathrm{CHP}}, \forall t \in T \\
0 \leq W_{f, t}^{D A} \leq W_{f, t}^{\max }, \forall f \in \Omega^{\mathrm{WF}}, \forall t \in T \\
-P_{n m}^{\max } \leq B_{n m}\left(\delta_{n, t}^{D A}-\delta_{m, t}^{D A}\right) \leq P_{n m}^{\max }, \forall n, m \in \Lambda^{\mathrm{EPS}}, \forall t \in T \\
P_{j, t-1}^{\mathrm{CHP}, \mathrm{DA}}-P_{j, t}^{\mathrm{CHP}, \mathrm{DA}} \leq R L D_{j}^{\mathrm{CHP}}, \forall j \in \Omega^{\mathrm{CHP}}, \forall t \in T \\
P_{j, t}^{\mathrm{CHP}, \mathrm{DA}}-P_{j, t-1}^{\mathrm{CHPA}, \mathrm{DA}} \leq R L U_{j}^{\mathrm{CHP}}, \forall j \in \Omega^{\mathrm{CHP}}, \forall t \in T \\
\delta^{D A}{ }_{\mathrm{REF}, t}=0, \forall t \in T
\end{gathered}
$$

The first-stage constraints of DHS include (9)-(22). The constraints can be split into hydraulic constraints (9), thermal constraints (10)-(12) and scheduling operating constraints (13)-(15). Eq. (9) is the nodal mass flow balance equation. Eq. (10) is the heat balance equation, which combines CHP, heat demand, and heat storage. Eq. (11) describes the temperature drop in the pipeline caused by the heat loss, where parameter $\lambda$ depends on the diameter and heat transfer coefficient of pipelines. Eq. (12) describes the temperature mixing at each node. Eqs. (13)-(15) limit the CHP heat production capacity, mass flow rate, and temperature range.

Due to the heat storage tank integrated into the DHS, the heat storage balance equation is shown in Eq. (16) and the operational limits and capacity are shown in Eqs. (17)-(22). Operational constraints of heat storage ensure that only one process, charging or discharging, can take place at a time [41]. The purpose of the heat storage is to provide flexibility to the EPS and DHS. The heat can be stored according to the heat stock operational limits (19). 


$$
\begin{aligned}
& \sum_{m \in \Lambda_{n}} m_{m n, t}^{D A}=0, \forall m \in \Lambda^{\mathrm{DHS}}, \forall t \in T \\
& \sum_{j \in \Omega_{n}^{\mathrm{CHP}}} H_{j, t}^{\mathrm{CHP}, \mathrm{DA}}+\sum_{h \in \Omega_{n}^{\mathrm{HS}}}\left(H_{h, t}^{\mathrm{HS}, \mathrm{in}, \mathrm{DA}}-H_{h, t}^{\mathrm{HS}, \mathrm{out}, \mathrm{DA}}\right)-\sum_{l \in \Omega_{n}^{\mathrm{HL}}} H_{l, t}^{\mathrm{HL}}=c \cdot m_{m n, t}^{D A} \cdot\left(\tau_{m n, t}^{i n, D A}-\tau_{m n, t}^{\text {out }, D A}\right), \quad \forall m \in \Lambda^{\mathrm{DHS}}, \forall t \in T \\
& \tau_{m n, t}^{i n, D A}-\tau_{m n, t}^{\mathrm{a}}=e^{\frac{-\lambda_{m, t} L_{m n}}{c c_{m n, t, 0}}}\left(\tau_{m n, t}^{\text {out, } D A}-\tau_{m n, t}^{\mathrm{a}}\right), \forall m, n \in \Lambda^{\mathrm{DHS}}, \forall t \in T \\
& \tau_{m, t}^{\text {out }, D A} \sum_{m \in \Lambda_{n}} m_{m n, t}^{D A}=\sum_{m \in \Lambda_{n}}\left(m_{n m, t}^{D A} \cdot \tau_{n m, t}^{i n, D A}\right), \forall m \in \Lambda^{\mathrm{DHS}}, \forall t \in T \\
& H_{j}^{\mathrm{CHP}, \min } \leq H_{j, t}^{\mathrm{CHP}, \mathrm{DA}} \leq H_{j}^{\mathrm{CHP}, \max }, \forall j \in \Omega^{\mathrm{CHP}}, \forall t \in T \\
& m_{m n}^{\min } \leq m_{m n, t}^{D A} \leq m_{m n, t}^{\max }, \forall m, n \in \Lambda^{\mathrm{DHS}}, \forall t \in T \\
& \tau_{m n}^{\text {in/out,min }} \leq \tau_{m n, t}^{\text {in/Dut,DA }} \leq \tau_{m n}^{\text {in/out,max }}, \forall m, n \in \Lambda^{\mathrm{DHS}}, \forall t \in T \\
& H S_{h, t+1}^{D A}=H S_{h, t}^{D A}+\left(H_{h, t}^{\mathrm{HS}, \mathrm{out}, \mathrm{DA}}-H_{h, t}^{\mathrm{HS}, \mathrm{in}, \mathrm{DA}}\right), \quad \forall h \in \Omega^{\mathrm{HS}}, \forall t \in T \\
& H_{h}^{\mathrm{HS}, \mathrm{in}, \mathrm{min}} x_{h, t}^{\mathrm{HS}, \mathrm{in}, \mathrm{DA}} \leq H_{h, t}^{\mathrm{HS}, \mathrm{in}, \mathrm{DA}} \leq H_{h}^{\mathrm{HS}, \mathrm{in}, \max } x_{h, t}^{\mathrm{HS}, \mathrm{in}, \mathrm{DA}}, \forall h \in \Omega^{\mathrm{HS}}, \forall t \in T \\
& H_{h}^{\mathrm{HS}, \text { out,min }} x_{h, t}^{\mathrm{HS}, \text { out,DA}} \leq H_{h, t}^{\mathrm{HS}, \text { out,DA}} \leq H_{h}^{\mathrm{HS}, \text { out,max }} x_{h, t}^{\mathrm{HS}, \text { out,DA }}, \forall h \in \Omega^{\mathrm{HS}}, \forall t \in T \\
& H S_{h}^{\min } \leq H S_{h, t}^{D A} \leq H S_{h}^{\max }, \forall h \in \Omega^{\mathrm{HS}}, \forall t \in T \\
& x_{h, t}^{\mathrm{HS}, \mathrm{out}, \mathrm{DA}}+x_{h, t}^{\mathrm{HS}, \mathrm{in}, \mathrm{DA}} \leq 1, \quad \forall h \in \Omega^{\mathrm{HS}}, \forall t \in T \\
& x_{h, t}^{\mathrm{HS}, \mathrm{out}, \mathrm{DA}} \in\{0,1\}, \forall h \in \Omega^{\mathrm{HS}}, \forall t \in T \\
& x_{h, t}^{\mathrm{HS}, \mathrm{in}, \mathrm{DA}} \in\{0,1\}, \forall h \in \Omega^{\mathrm{HS}}, \forall t \in T
\end{aligned}
$$

Correspondingly, the first-stage constraints of the NGS include (23)-(35). The nodal gas balance equation, Eq. (24), consists of a gas source and P2G unit as generating units, demands, gas compressor, and storage. The flow equation for the pipelines is shown in Eq. (23) where, on the reference node, the pressure is fixed. As an addition, the gas compressor is implemented in the NGS to control and manage the gas flow. The fuel for the gas compressor used is the gas and the energy consumption by the gas compressor is given in Eq. (25). The operational limits of the gas source and P2G unit are shown in Eqs. (26) and (27), respectively. The limits of the NGS regarding gas pressure and gas flow are included in Eqs. (28)-(29). The gas storage balance and capacity limits are presented in Eqs. (30) and (36). Due to only one process being available at a time, the binary variables for incoming and outgoing gas to and from the gas storage are included in Eqs. (31)-(35) [41].

$$
\begin{gathered}
\left(p_{n, t}^{D A}\right)^{2}-\left(p_{m, t}^{D A}\right)^{2}=Z_{n m}\left(S_{n m, t}^{D A}\right)^{2}, \forall n, m \in \Lambda^{\mathrm{NGS}}, \forall t \in T \\
\sum_{g \in \Omega_{n}^{\mathrm{GS}}} Q_{g, t}^{\mathrm{GS}, \mathrm{DA}}+\sum_{s \in \Omega_{n}^{\mathrm{ST}}}\left(Q_{s, t}^{\mathrm{ST}, \mathrm{ou}, \mathrm{DA}}-Q_{s, t}^{\mathrm{ST}, \mathrm{in}, \mathrm{DA}}\right)+\sum_{k \in \Omega_{n}^{\mathrm{P} 2 \mathrm{G}}} Q_{k, t}^{\mathrm{P} 2 \mathrm{G}, \mathrm{DA}} \\
-\sum_{d \in \Omega_{n}^{\mathrm{Gi}}} D_{d, t}^{\mathrm{GD}}-\sum_{g \in \Omega_{n}^{\mathrm{GC}}} D_{g, t}^{\mathrm{GC}, \mathrm{DA}}-\sum_{j \in \Omega_{n}^{\mathrm{CHP}}} D_{j, t}^{\mathrm{CH}, \mathrm{DA}}=\sum_{m \in \Lambda_{n}} S_{n m, t}^{D A}, \forall n, m \in \Lambda^{\mathrm{NGS}}, \forall t \in T \\
D_{g, t}^{\mathrm{GC}, \mathrm{DA}}=\lambda_{g}^{\mathrm{GC}} S_{g, t}^{\mathrm{GC}, \mathrm{DA}}=K^{\mathrm{GC}} Z_{\mathrm{a}}\left[\frac{T_{s}}{E^{\mathrm{GC}} \eta^{\mathrm{GC}}}\right]\left[\frac{c_{k}}{c_{k}-1}\right]\left[(C R)^{\frac{c_{k}-1}{c_{k}}}-1\right] S_{g, t}^{\mathrm{GC}, \mathrm{DA}}, \forall g \in \Omega^{\mathrm{GC}}, \forall t \in T \\
Q_{g}^{\mathrm{GS}, \min } \leq Q_{g, t}^{\mathrm{GS}, \mathrm{DA}} \leq Q_{g}^{\mathrm{GS}, \max }, \forall g \in \Omega^{\mathrm{GS}}, \forall t \in T \\
Q_{k}^{\mathrm{P} 2 \mathrm{G}, \min } \leq Q_{k, t}^{\mathrm{P} 2 \mathrm{G}, \mathrm{DA}} \leq Q_{k}^{\mathrm{P} 2 \mathrm{G}, \max }, \forall k \in \Omega^{\mathrm{P} 2 \mathrm{G}}, \forall t \in T \\
\left(p_{n, t}^{2}\right)^{\min } \leq\left(p_{n, t}^{D A}\right)^{2} \leq\left(p_{n, t}^{2}\right)^{\max }, \forall n \in \Lambda^{\mathrm{NGS}}, \forall t \in T \\
-S_{n m}^{\max } \leq S_{n m, t}^{D A} \leq S_{n m}^{\max }, \forall m, n \in \Lambda^{\mathrm{NGS}}, \forall t \in T
\end{gathered}
$$




$$
\begin{gathered}
S T_{s, t+1}^{D A}=S T_{s, 0}^{D A}+\sum_{t=1}^{t}\left(Q_{s, t}^{\mathrm{ST}, \text { in,DA }}-Q_{s, t}^{\mathrm{ST}, \text { out }, \mathrm{DA}}\right), \quad \forall s \in \Omega^{\mathrm{ST}}, \forall t \in T \\
0 \leq Q_{s, t}^{\mathrm{ST}, \mathrm{in}, \mathrm{DA}} \leq Q_{s}^{\mathrm{ST}, \text { in,max }} x_{s, t}^{\mathrm{ST}, \text { in,DA }}, \forall s \in \Omega^{\mathrm{ST}}, \forall t \in T \\
0 \leq Q_{s, t}^{\mathrm{ST}, \mathrm{ou}, \mathrm{DA}} \leq Q_{s}^{\mathrm{ST}, \text { out,max }} x_{s, t}^{\mathrm{ST}, \text { out }, \mathrm{DA}}, \forall s \in \Omega^{\mathrm{ST}}, \forall t \in T \\
x_{s, t}^{\mathrm{ST}, \mathrm{in}, \mathrm{DA}}+x_{s, t}^{\mathrm{ST}, \text { out,DA}} \leq 1, \quad \forall s \in \Omega^{\mathrm{ST}}, \forall t \in T \\
x_{s, t}^{\mathrm{ST}, \mathrm{in}, \mathrm{DA}} \in\{0,1\}, \quad \forall s \in \Omega^{\mathrm{ST}}, \forall t \in T \\
x_{s, t}^{\mathrm{ST}, \text { out }, \mathrm{DA}} \in\{0,1\}, \quad \forall s \in \Omega^{\mathrm{ST}}, \forall t \in T \\
S T_{s}^{\text {min }} \leq S T_{s, t}^{D A} \leq S T_{s}^{\mathrm{max}}, \forall s \in \Omega^{\mathrm{ST}}, \forall t \in T
\end{gathered}
$$

The gas flow unit is $\mathrm{m}^{3} / \mathrm{h}$ and Eq. (37) is used to obtain the power unit MW in this work for the conversion to the p.u. system [13]. The LHV represents a lower heating value and is equal to $37.26 \mathrm{MJ} / \mathrm{m}^{3}$.

$$
S_{n m, t}=G_{n m, t} \frac{L H V}{3600}, \forall m, n \in \Lambda^{\mathrm{NGS}}, \forall t \in T
$$

In addition, in Eq. (25), the energy consumption by the gas compressor is given in horsepower. In order to obtain the p.u. value, the horsepower system must be obtained through the conversion from $\mathrm{m}^{3} / \mathrm{h}$ to million standard cubic feet per day and on the conversion from horsepower to MW must be done.

\subsection{Second-stage constraints}

In this subsection, the second-stage constraints of the EPS, DHS and NGS are separately shown. The explanation will be only given for supplementary constraints as the second-stage constraints of each energy system are similar to those in the first stage.

The RT-stage constraints of the EPS include (38)-(47). Eq. (38) represents the nodal power balance in the RT as the difference between power consumed and generated in DA and RT. In addition, upward and downward reserves, wind spillage and load shedding might be activated. Wind power output in RT equals to the generated scenarios in this work. The RT stage is, therefore, calculated for each of the scenarios. Eq. (39) describes transmission lines capacity. Eq. (40) is limiting the output power of CHP accounting for the reserves and Eqs. (41)-(42) are capacity limits for reserves. Eqs. (43) and (44) represent the ramping ability of CHP units. Limits of the wind spillage and load shedding are shown in Eqs. (45) and (46), respectively. Eq. (47) describes the angle constraint of the reference bus.

$$
\begin{aligned}
& \sum_{j \in \Omega_{n}^{\mathrm{CHP}}}\left(R_{j, \omega, t}^{\mathrm{CHP}, \mathrm{U}}-R_{j, \omega, t}^{\mathrm{CHP}, \mathrm{D}}\right)+\sum_{f \in \Omega_{n}^{\mathrm{WF}}}\left(W_{f, \omega, t}^{R T}-W_{f, \omega, t}^{\text {spill }}-W_{f, t}^{\mathrm{DA}}\right)-\sum_{k \in \Omega_{n}^{\mathrm{P} \mathrm{CG}}}\left(D_{k, \omega, t}^{\mathrm{P} 2 \mathrm{G}, \mathrm{RT}}-D_{k, t}^{\mathrm{P} 2 \mathrm{G}, \mathrm{DA}}\right) \\
& +\sum_{e \in \Omega_{n}^{\mathrm{ED}}} D_{e, \omega, t}^{\mathrm{ED}, \text { shed }}=\sum_{m \in \Lambda_{n}} B_{n m}\left(\delta_{n, \omega, t}^{R T}-\delta_{m, \omega, t}^{R T}-\delta_{n, t}^{D A}+\delta_{m, t}^{D A}\right), \quad \forall n \in \Lambda^{\mathrm{EPS}}, \forall t \in T, \forall \omega \in \Theta \\
& -P_{n m}^{\max } \leq B_{n m}\left(\delta_{n, \omega, t}^{R T}-\delta_{m, \omega, t}^{R T}\right) \leq P_{n m}^{\max }, \forall n, m \in \Lambda^{\mathrm{EPS}}, \forall t \in T, \forall \omega \in \Theta \\
& P_{j, t}^{\mathrm{CHP}, \min } \leq P_{j, t}^{\mathrm{CHP}, \mathrm{DA}}+\left(R_{j, \omega, t}^{\mathrm{CHP}, \mathrm{U}}-R_{j, \omega, t}^{\mathrm{CHP}, \mathrm{D}}\right) \leq P_{j, t}^{\mathrm{CHP}, \max }, \forall j \in \Omega^{\mathrm{CHP}}, \forall t \in T, \forall \omega \in \Theta \\
& 0 \leq R_{j, \omega, t}^{\mathrm{CHP}, \mathrm{U}} \leq R_{j, t}^{\mathrm{CHP}, \mathrm{U}, \mathrm{max}}, \forall j \in \Omega^{\mathrm{CHP}}, \forall t \in T, \forall \omega \in \Theta \\
& 0 \leq R_{j, \omega, t}^{\mathrm{CHP}, \mathrm{D}} \leq R_{j, t}^{\mathrm{CHP}, \mathrm{D}, \max }, \forall j \in \Omega^{\mathrm{CHP}}, \forall t \in T, \forall \omega \in \Theta \\
& P_{j, t-1}^{\mathrm{CHP}, \mathrm{DA}}+\left(R_{j, \omega, t-1}^{\mathrm{CHP}}-R_{j, \omega, t-1}^{\mathrm{CHP}, \mathrm{D}}\right)-P_{j, t}^{\mathrm{CHP}, \mathrm{DA}}-\left(R_{j, \omega, t}^{\mathrm{CHP}, \mathrm{U}}-R_{j, \omega, t}^{\mathrm{CHP}, \mathrm{D}}\right) \leq R L D_{j}^{\mathrm{CHP}}, \forall j \in \Omega^{\mathrm{CHP}}, \forall t \in T, \forall \omega \in \Theta \\
& P_{j, t}^{\mathrm{CHP}, \mathrm{DA}}+\left(R_{j, \omega, t}^{\mathrm{CHP}, \mathrm{U}}-R_{j, \omega, t}^{\mathrm{CHP}, \mathrm{D}}\right)-P_{j, t-1}^{\mathrm{CHP}, \mathrm{DA}}-\left(R_{j, \omega, t-1}^{\mathrm{CHP}, \mathrm{U}}-R_{j, \omega, t-1}^{\mathrm{CHP}, \mathrm{D}}\right) \leq R L U_{j}^{\mathrm{CHP}}, \forall j \in \Omega^{\mathrm{CHP}}, \forall t \in T, \forall \omega \in \Theta \\
& 0 \leq W_{f, \omega, t}^{\text {spill }} \leq W_{f, \omega, t}^{R T}, \forall f \in \Omega^{\mathrm{WF}}, \forall t \in T, \forall \omega \in \Theta \\
& 0 \leq D_{e, \omega, t}^{\mathrm{ED}, \text { shed }} \leq D_{e, t}^{\mathrm{ED}}, \forall e \in \Omega^{E D}, \forall t \in T, \forall \omega \in \Theta
\end{aligned}
$$




$$
\delta_{\mathrm{REF}, \omega, t,}^{R T}=0, \forall t \in T, \forall \omega \in \Theta
$$

Due to wind uncertainty, CHP production varies and influences heat generation in the DHS. As the heat source is affected, the heat storage input and output values for heat can also differ from the DA stage. Consequently, mass flow and temperature at each node can vary. All the variables having the RT superscript are dependent on the scenario. The slight difference can be seen in Eq. (48). Thus, the remainder of the equations is not shown as it is similar to Eqs. (9), (11)-(22).

$$
\begin{gathered}
\sum_{j \in \Omega_{n}^{\mathrm{CHP}}}\left(H_{j, \omega, t}^{\mathrm{CHP}, \mathrm{RT}}-H_{j, t}^{\mathrm{CHP}, \mathrm{DA}}\right)+\sum_{h \in \Omega_{n}^{\mathrm{HS}}}\left(H_{h, \omega, t}^{\mathrm{HS}, \mathrm{in}, \mathrm{RT}}-H_{h, \omega, t}^{\mathrm{HS}, \mathrm{ou}, \mathrm{RT}}-H_{h, t}^{\mathrm{HS}, \mathrm{in}, \mathrm{DA}}+H_{h, t}^{\mathrm{HS}, \mathrm{out}, \mathrm{DA}}\right)= \\
=\left[c \cdot m_{m n, \omega, t}^{R T} \cdot\left(\tau_{m n, \omega, t}^{i n, R T}-\tau_{m n, \omega, t}^{\text {out } R T}\right)\right]-\left[c \cdot m_{m n, t}^{D A} \cdot\left(\tau_{m n, t}^{i n, D A}-\tau_{m n, t}^{\text {out }, D A}\right)\right], \forall m \in \Lambda^{\mathrm{DHS}}, \forall t \in T, \forall \omega \in \Theta
\end{gathered}
$$

Nodal gas balance is the difference between the RT stage and DA stage for each variable as in Eq. (49). The additional variables are upward and downward reserves provided by the P2G unit. Due to additional reserves, the limit of $\mathrm{P} 2 \mathrm{G}$ output considers the DA stage of $\mathrm{P} 2 \mathrm{G}$ output and reserves (50). P2G reserve capacity is limited in Eqs. (51)-(52). The remainder of the equations is not shown as it is similar to Eqs. (23), (25)-(26) and (29)-(36) with superscript in the RT stage.

$$
\begin{gathered}
\sum_{g \in \Omega_{n}^{\mathrm{GS}}}\left(Q_{g, \omega, t}^{\mathrm{GS}, \mathrm{RT}}-Q_{g, t}^{\mathrm{GS}, \mathrm{DA}}\right)+\sum_{s \in \Omega_{n}^{\mathrm{ST}}}\left(Q_{s, \omega, t}^{\mathrm{ST}, \mathrm{ou}, \mathrm{RT}}-Q_{s, \omega, t}^{\mathrm{ST}, \text { in, RT }}-Q_{s, t}^{\mathrm{ST}, \mathrm{out}, \mathrm{DA}}+Q_{s, t}^{\mathrm{ST}, \mathrm{in}, \mathrm{DA}}\right)+\sum_{k \in \Omega_{n}^{\mathrm{P} \text { PG }}}\left(R_{k, \omega, t}^{P 2 G, U}-R_{k, \omega, t}^{P 2 G, D}\right)- \\
\sum_{g \in \Omega_{n}^{\mathrm{GC}}}\left(D_{g, \omega, t}^{\mathrm{GC}, \mathrm{RT}}-D_{g, t}^{\mathrm{GC}, \mathrm{DA}}\right)-\sum_{j \in \Omega_{n}^{\mathrm{CP}}}\left(D_{j, \omega, t}^{\mathrm{CHP}, \mathrm{RT}}-D_{j, t}^{\mathrm{CHP}, \mathrm{DA}}\right)=\sum_{m \in \Lambda_{n}}\left(S_{n m, \omega, t}^{R T}-S_{n m, t}^{D A}\right), \forall m, n \in \Lambda^{\mathrm{NGS}}, \forall t \in T, \forall \omega \in \Theta \\
Q_{k}^{\mathrm{P} 2 \mathrm{G}, \min } \leq Q_{k, t}^{\mathrm{P} 2 \mathrm{G}, \mathrm{DA}}+\left(R_{k, \omega, t}^{P 2 G, U}-R_{k, \omega, t}^{P 2 G, D}\right) \leq Q_{k}^{\mathrm{P} 2 \mathrm{G}, \max }, \forall k \in \Omega^{\mathrm{P} 2 \mathrm{G}}, \forall t \in T, \forall \omega \in \Theta \\
0 \leq R_{k, \omega, t}^{P 2 G, U} \leq R_{k, t}^{\mathrm{P} 2 \mathrm{G}, \mathrm{U}, \max }, \forall k \in \Omega^{\mathrm{P} 2 \mathrm{G}}, \forall t \in T, \forall \omega \in \Theta \\
0 \leq R_{k, \omega, t}^{P 2 G, D} \leq R_{k, t}^{\mathrm{P} 2 \mathrm{G}, \mathrm{D}, \max }, \forall k \in \Omega^{\mathrm{P} 2 \mathrm{G}}, \forall t \in T, \forall \omega \in \Theta
\end{gathered}
$$

\subsection{Coupling components}

Coupling components are used as a linkage between multiple energy sectors and constraints are considered in both stages. From the previous equations, it can be seen that two coupling components are used. The CHP unit generates electricity and heat by consuming natural gas from the NGS. The energy conversion relationship between the gas consumption of the CHP, electricity, and heat is shown in Eqs. (53)-(58). In this work, the P2G unit is considered as one direction energy conversion unit. P2G consumes excessive electricity from wind power and produces hydrogen. It is considered that gas can be injected in the NGS.

$$
\begin{gathered}
P_{j, t}^{\mathrm{CHP}, \mathrm{DA}}=D_{j, t}^{\mathrm{CHP}, \mathrm{DA}} \eta_{j}^{\mathrm{e}}, \quad \forall j \in \Omega^{\mathrm{CHP}}, \forall t \in T \\
H_{j, t}^{\mathrm{CHP}, \mathrm{DA}}=D_{j, t}^{\mathrm{CHP}, \mathrm{DA}} \eta_{j}^{h}, \quad \forall j \in \Omega^{\mathrm{CHP}}, \forall t \in T \\
Q_{k, t}^{\mathrm{P} 2 \mathrm{DA}}=\eta_{k}^{\mathrm{P} 2 \mathrm{G}} D_{k, t}^{\mathrm{P} 2 \mathrm{G}, \mathrm{DA}}, \forall k \in \Omega^{\mathrm{P} 2 \mathrm{G}}, \forall t \in T \\
\left(R_{j, \omega, t}^{\mathrm{CHP}, \mathrm{U}}-R_{j, \omega, t}^{\mathrm{CH}, \mathrm{D}}\right)=\left(D_{j, \omega}^{\mathrm{CH}, t}-D_{j, t}^{\mathrm{CHP}, \mathrm{DA}}\right) \eta_{j}^{\mathrm{e}}, \quad \forall j \in \Omega^{\mathrm{CHP}}, \forall t \in T, \forall \omega \in \Theta \\
\left(H_{j, \omega, t}^{\mathrm{CH}, \mathrm{RT}}-H_{j, t}^{\mathrm{CHP}, \mathrm{DA}}\right)=\left(D_{j, \omega, t}^{\mathrm{CHP}, \mathrm{RT}}-D_{j, t}^{\mathrm{CHP}, \mathrm{DA}}\right) \eta_{j}^{h}, \quad \forall j \in \Omega^{\mathrm{CHP}}, \forall t \in T, \forall \omega \in \Theta \\
Q_{k, t}^{\mathrm{P} 2 \mathrm{G}, \mathrm{DA}}+\left(R_{k, \omega, t}^{P 2 G, U}-R_{k, \omega, t}^{P 2 G, D}\right)=\eta_{k}^{\mathrm{P} 2 \mathrm{G}} D_{k, \omega, t}^{\mathrm{P} 2 \mathrm{G}, \mathrm{RT}}, \quad \forall k \in \Omega^{\mathrm{P} 2 \mathrm{G}}, \forall t \in T, \forall \omega \in \Theta
\end{gathered}
$$

The detailed mixed integer linear optimization problem is formulated in the General Algebraic Modeling System (GAMS) and solved by the CPLEX solver [42].

\subsection{Linearization procedure}


The linearization procedure for the DHS and NGS is presented in this section. Due to the non-linearity and non-convexity of the IES model presented in Section 2, it is not guaranteed that a global optimum is reached. Pipeline flow equation, Eq. (23), represented by the Weymouth equation is non-linear. Different approaches have been used to linearize the gas network. An iterative approach is presented in [16], Taylor series expansion in [43]-[44] and the piecewise linear approximation, extended and incremental formulation of Weymouth equation can be found in [45]-[48]. Using incremental formulation for the piecewise linearization has better performance in regards to computational speed compared to simple piecewise linearization. The NGS and review of piecewise linear approximations for gas pipeline flow are presented in [49]. Along with that, the benefits and drawbacks of each of the methods are discussed. In conclusion, the incremental method for piecewise linearization shows the best performance.

Due to pressure squared and known flows, the pressure at each node is substituted by $\pi_{m}$ [46]. The quadratic flow on the right side of the equation is then replaced by a piecewise linear function as follows.

$$
\begin{gathered}
\left(\pi_{n, t}^{D A}\right)-\left(\pi_{m, t}^{D A}\right)=Z_{n m}\left(S_{n m, t}^{D A}\right)^{2}, \quad \forall n, m \in \Lambda^{\mathrm{NGS}}, \forall t \in T \\
h\left(S_{n m, t}^{D A}\right)=\left(S_{n m, t}^{D A}\right)^{2}, \quad \forall n, m \in \Lambda^{\mathrm{NGS}}, \forall t \in T,-S_{n m}^{\max } \leq S_{n m, t}^{D A} \leq S_{n m}^{\max } \\
h\left(S_{n m, t}^{D A}\right) \approx h\left(S_{1}\right)+\sum_{i=1}^{p}\left(h\left(S_{i+1}\right)-h\left(S_{i}\right)\right) \delta_{i}, \quad i \in \mathrm{P}, \forall t \in T, \forall n, m \in \Lambda^{\mathrm{NGS}} \\
S_{n m, t}^{D A}=S_{1}+\sum_{i=1}^{p}\left(S_{i+1}-S_{i}\right) \delta_{i}, \quad \forall i \in \mathrm{P}, \forall t \in T, \forall n, m \in \Lambda^{\mathrm{NGS}} \\
0 \leq \delta_{i} \leq 1, \quad \forall i \in \mathrm{P} \\
x_{i} \leq \delta_{i}, \quad x_{i} \geq \delta_{i+1}, \quad \forall i \in \mathrm{P}-1 \\
\delta_{i} \in[0,1], \quad \forall i \in \mathrm{P} \\
x_{i} \in\{0,1\}, \quad \forall i \in \mathrm{P}-1 \\
S_{i} \in\left[-S_{n m}^{\max }, S_{n m}^{\max }\right], \quad \forall i \in \mathrm{P}
\end{gathered}
$$

$P$ denotes the set of segments, $S_{i}$ point chosen for the piecewise linearization and $x_{i}$ denotes a binary variable for forcing the filling conditions for each point of the segment. $\delta$ is the portion of each segment.

Regarding the heating network, more non-linear terms can be noticed. By using Taylor first order approximation for two and three variables, the terms can be replaced.

\section{Temporal-correlated scenario generation of wind power for IES scheduling model}

The scenario set for stochastic programming represents the uncertainty of wind power and decides the reserve capacity requirement. Therefore, it has a great influence on the decision results. The existing work for the IES considering wind power uncertainty neglects the temporal correlation of wind power scenarios, which may fail to obtain the optimal operation point of the IES. Ref. [37] proposed an advanced scenario set with the temporal correlation taken into account. However, the influence of the scenario set on the economical efficiency of the IES has not been exploited. The temporal-correlated scenario set is adopted in this work to achieve a more reliable and economical decision. The scenario generation method consists of a few steps.

\subsection{Historical data used in the study}

In this study, the data of measured and forecasted wind power have to be included. Hence, the data of two years from a European transmission system operator (TSO), Tennet, are used. Tennet operates in the Netherlands and a large part of Germany. The data contains aggregated measured and forecasted values of 
wind power from 00:00 on April 30th, 2017 to 23:45 April 30th, 2019. The resolution of the data is 15 minutes which makes 96 measurements per day leading to 96 point forecasts in each scenario. Therefore, the matrix of size [70176 x 2] is built where columns are historical data pairs as [measured historical data (MHD), forecasted historical data (FHD)]. The entire dataset for two years is normalized by dividing it with the maximum value of the data.

\subsection{Building the data box using historical data}

In order to obtain future realizations of scenarios, distribution for a given point forecast of wind output power is necessary. A distribution for a given point forecast of wind power output is performed by introducing a data box containing equally separated power bins, each associated with a certain range of forecasted power. The number of power bins in the data box is dependent on the bin width and the number of the data available. The data box in this paper consists of 50 power bins with a width 0.02 p.u. since the data is normalized based on its maximum value. In order to build the data box which contains the mentioned power bins, the historical data pairs, MHD and FHD, are sorted by FHD values, and the FHD values are assigned to the matching power bin with their corresponding MHD values. The power bins are represented as cells containing the assigned FHD values with their corresponding MHD such that the whole data box consists of 50 cells. As an illustration, for the data chosen in this study, in the first power bin ranging from 0 to 0.02 p.u., there are 966 data pairs. Ranging from 0.38 p.u. to 0.4 p.u. in power bin 20 and from 0.88 p.u. to 0.9 p.u. in power bin 45 , there are 1722 and 320 data pairs, respectively. The distribution fits for the 6th and 44th bin are shown in Fig. 1. The MHD values inside each bin are not fitting appropriately to the theoretical distributions. Therefore, in order to characterize wind power uncertainty, a non-parametric estimate is created in the form of an empirical cumulative distribution function (ECDF) for the MHD inside each power bin. The ECDF is not assuming any theoretical distribution and is based on historical observations.
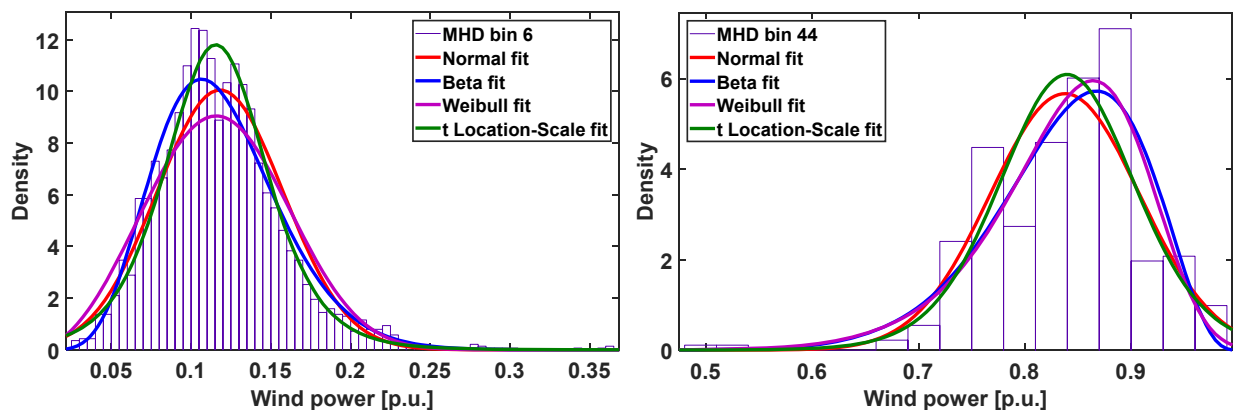

Fig. 1. Density of measured historical data and the fits according to Normal and beta distribution for bin 6 and bin 44

\subsection{Gaussian random vector}

The Gaussian random vector is generated based on a normal distribution with zero mean and covariance matrix, $\sim \mathrm{N}(0, \Sigma)$. Firstly, the covariance matrix is calculated. Afterward, the Gaussian random vector is generated. To calculate the covariance matrix, parameter epsilon, $\varepsilon$, is required.

\subsubsection{Calculation of parameter epsilon}

The parameter epsilon, $\varepsilon$, is used in the equation to calculate the covariance matrix to control the correlation between the two random time variables in order to follow wind variability for generated scenarios. To attain parameter $\varepsilon$, MHD and generated scenarios are used. Firstly, wind power ramping between two time intervals of MHD is calculated as a difference between a wind power output at time $t$ and wind power output at time $t+1$. Once the ramping of MHD is obtained, the distribution fit can be found. According to the 
existing studies, the best approximation of distribution fitting for wind power ramping of the MHD is achieved with $\mathrm{t}$ the location-scale distribution compared to the normal, logistic or extreme value distributions [37]-[38]. Since the distribution fit is dependent on the data, verification of the statement is performed for the MHD values used in this work. The distribution histogram of the MHD of wind power ramping and fitting distributions are shown in Fig. 2.

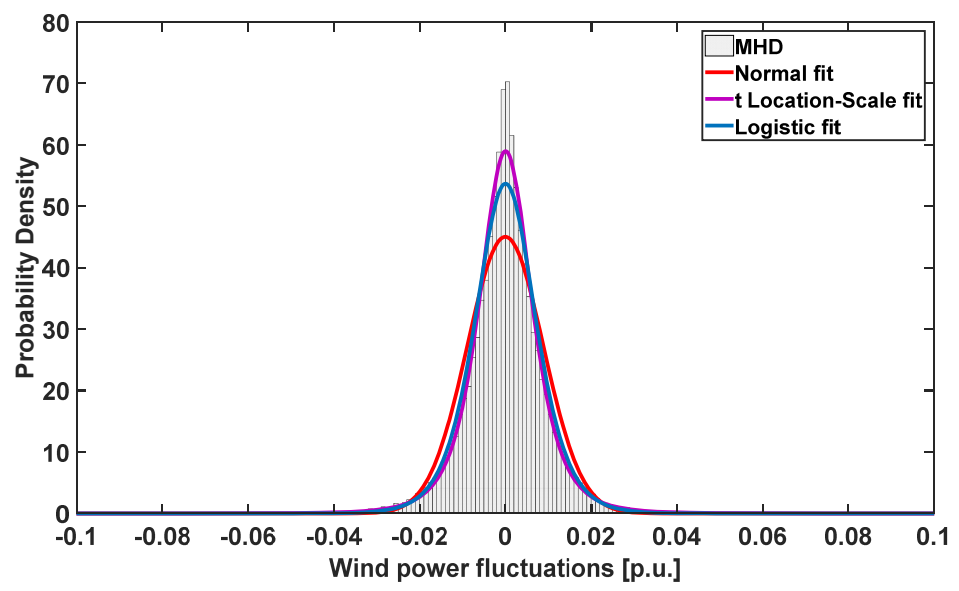

Fig. 2. Distribution histogram of measured historical wind power ramping and distribution fits

It can be observed that the best distribution fit to the MHD for wind power ramping is the tocation-scale fit as mentioned. Therefore, by fitting $t$ location-scale distribution to the MHD of wind power ramping, the probability distribution object is created. The probability density function (pdf) values are computed for the $t$ location-scale distribution object at a sampling size of 1000 in the interval -0.15 to 0.15 according to [34]. Regarding the generated scenarios, scenarios are generated based on the same procedure for the SG technique in this work with the difference of having a variable parameter epsilon. Once the scenarios are generated, the wind power possible fluctuations within each time interval for generated scenarios are calculated. The $t$ location-scale distribution is fitted to the wind power ramping of generated scenarios and pdf values are computed at the equal sampling size as mentioned.

The indicator epsilon, $\mathrm{I}_{\varepsilon}$, is used to determine the best possible $\varepsilon$ to be used for SG. According to [37], $\mathrm{I}_{\varepsilon}$ is calculated as a sum of the absolute value of a difference between the pdf of the wind power ramping of the MHD and pdf of the wind power ramping of generated scenarios. The sum is further divided by the sampling size of $1000 . I_{\varepsilon}$ is computed for each value of epsilon. As it is desired to have a lower difference of the wind power ramping between MHD and generated data, $\varepsilon$ is taken for the smallest $\mathrm{I}_{\varepsilon}$. Epsilon for the value of $I_{\varepsilon}$ lower than 0.5 is acceptable.

\subsubsection{Covariance matrix calculation}

The covariance matrix is representing the correlation between wind power at two periods called temporal correlation. The covariance matrix is a positive definite matrix and its size is dependent on the maximum forecasting period. The covariance matrix is shown below where $\mathrm{H}$ denotes maximum forecasting horizon. In this work, the covariance matrix is of size $[96,96]$.

$$
\Sigma=\left[\begin{array}{cccc}
\sigma_{1,1} & \sigma_{1,2} & \cdots & \sigma_{1, H} \\
\sigma_{2,1} & \sigma_{2,2} & \cdots & \sigma_{2, H} \\
\vdots & \vdots & \ddots & \vdots \\
\sigma_{H, 1} & \sigma_{H, 2} & \cdots & \sigma_{H, H}
\end{array}\right]
$$


Where covariance is

$$
\sigma_{R i, R j}=\operatorname{cov}\left(R_{i}, R_{j}\right)=e^{-\frac{|i-j|}{\varepsilon}} \quad, 0 \leq n, \quad m \leq H
$$

$\mathrm{R}$ is denoting random variables. Once the covariance matrix is obtained, the Gaussian random vector can be generated. The number of scenarios generated is 500 for each point forecast. Therefore, the vector size of the generated scenarios is $[500,96]$

\subsection{Inverse transformation}

Inverse transformation is sampling the scenarios around the point forecasts. Firstly, a day in historical data is chosen and normalized. Moreover, for the chosen day, the bin numbers for each lead time of the point forecasts are found. Finally, bin numbers indicate which ECDF of MHD values will be used for inverse distribution transformation. Secondly, cumulative distribution function (CDF) for standard normal distribution evaluated at the multivariate random scenarios values, is considered. Hence, for each lead time for the number of the scenarios of random vectors, inverse transformation is performed [50]. Finally, wind power realizations can be converted to the power unit.

The backward scenario reduction technique is used to reduce the initial number of scenarios. A schematic overview of the proposed SG method and the proposed two-stage scheme is shown in Fig. 3.

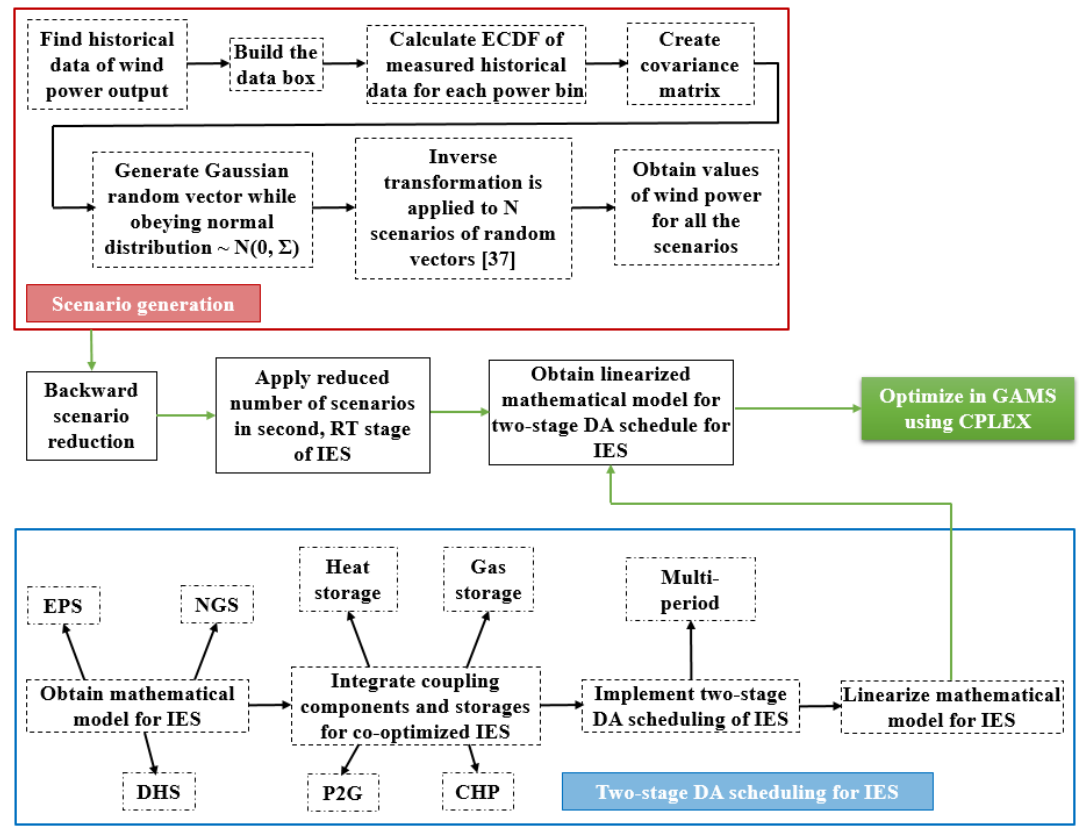

Fig. 3. Overview of the proposed method and procedure for obtaining day-ahead scheduling results

\section{Case study \\ 4.1. Case description}

In this section, the test system and parameter data are presented. The test case system and its parameters can be found in Appendix A. The historical data of demand in EPS, DHS and NGS can be found at Energinet's (Danish TSO) webpage and in [51] as well. The demand was appropriately scaled to fit the test system. According to [52], the parameter of the electricity-heat ratio is used for the CHP unit and, the 
constraint for linking heat and electricity is made. The costs of upward and downward reserves are given in [53] and reserves costs are equal to 1.1 and 0.9 of DA scheduling price respectively. Historical data of wind power output used in the scenario generation can be found in [54].

For the case study and comparison, two days are taken from the data in order to generate scenarios. $\varepsilon$ should be updated based on the day-ahead forecasts for the chosen day. As the day ahead scheduling is considered, in reality, a forecast for the next day should be chosen. Therefore, $\varepsilon$ should be updated based on the dayahead forecasts. The representative days consider high and low wind power output forecasts obtained on August $7^{\text {th }}, 2017$ and June $8^{\text {th }}, 2018$, respectively. Therefore, the relationships between indicator $\mathrm{I}_{\varepsilon}$ and $\varepsilon$ for high and low wind power output forecasts are shown in Fig. 4 based on the explanations given in Section 3.3.1. Both values of epsilon, 111 and 31 for high and low wind power forecast days respectively, are acceptable and used for calculation of the covariance matrix.

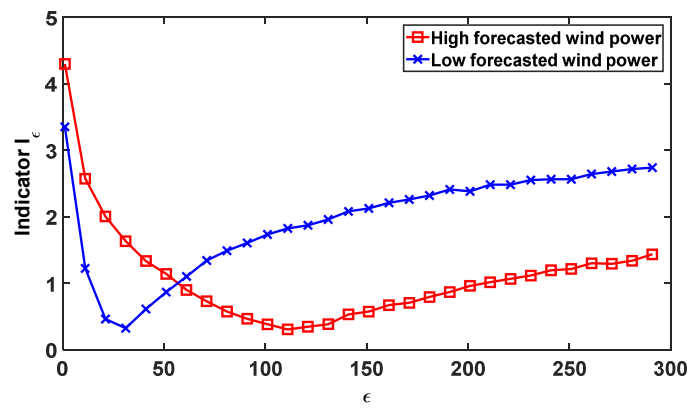

Fig. 4. Relationship between $\varepsilon$ and $I_{\varepsilon}$ for high and low wind power forecast

To validate the effectiveness of the proposed method, the following subsections present the simulation results. Section 4.2 investigates the influence of the stochastic programming method on the scheduling results of the IES in contrast to the deterministic scheduling. Section 4.3 evaluates the impact of flexibility synergy on improving economic efficiency and wind power utilization. Section 4.4 analyzes the influence of the temporal-correlated scenario set on the decision results and computational efficiency. Lastly, limitations and application of the proposed two-stage scheme and the SG method are discussed.

\subsection{Comparison of deterministic and stochastic approaches of IES}

In this section, results obtained by the deterministic and two-stage stochastic programming models are compared. Firstly, the differences in accommodating the uncertainties between the deterministic and the stochastic approaches are illustrated. In the deterministic approach, the DA scheduling is based on the single deterministic forecast, i.e., the scheduling does not consider uncertainties of wind power and load. In the real-time operation, there is a mismatch between the DA schedule and RT operation states due to uncertainties. Moreover, a specific amount of reserves must be set aside and the expected value of the cost for providing reserves is not included. However, the stochastic model, as formulated in Section 2, is taking into account uncertainties in order to decrease the difference between the DA scheduling and RT operation.

The DA economic benefits of the stochastic and the deterministic models are compared based on the value of stochastic solution (VSS). The VSS is quantifying the economic advantage of using a stochastic approach over a deterministic approach [55]. In order to obtain the VSS, an optimal solution of the stochastic problem is obtained. The uncertain parameter, wind power output realizations, are replaced by expected value and the problem becomes deterministic. The obtained deterministic problem with the expected value is calculated. Lastly, the first stage variables are fixed in the original stochastic problem. The fixed values are taken from the deterministic approached solved previously. Hence, the VSS is the difference between 
the objective function value of the deterministic problem and the original stochastic problem presented in Section 2.

The VSS with different numbers of reduced scenarios is presented in Fig 5. Due to the wind spillage cost, the VSS is similar for the low and high forecasted wind power. The VSS increases in both cases with an increase in the number of scenarios (NoS). The VSS is positive until the NoS is 70. The advantage of using the stochastic model is seen from NoS equals 10 to 70 . Therefore, it is not required to use a high NoS as the VSS drops to negative and using stochastic approach is no longer beneficial compared to deterministic.

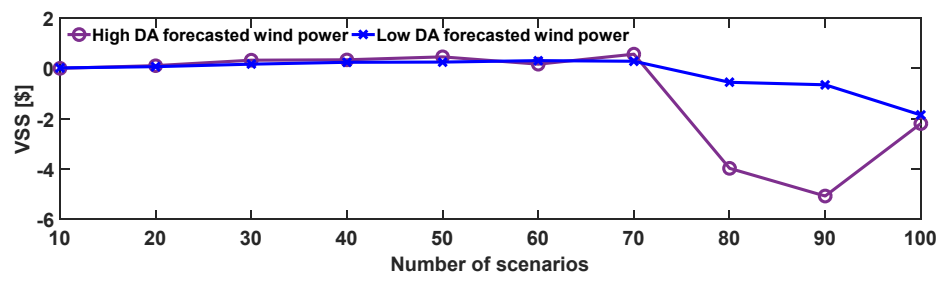

Fig. 5. VSS for high and low wind power forecast days for different number of reduced scenarios

It is shown that, by using a stochastic scheduling approach, a higher amount of future possible realizations is considered and reserves are optimized leading to a lower imbalance in RT compared to the deterministic approach. The benefits of stochastic programming approach are as follows. The DA clearing is based on a stochastic forecast of uncertain parameters. The expected system cost is lower and reserves are optimized. The two-stage stochastic programming approach shows the minimum operational costs compared to the deterministic one.

\subsection{Evaluation of the effect of the flexibility synergy}

To validate the effectiveness of the flexibility synergy, Table 2 lists the comparison for the operational cost and wind power utilization under different flexibility conditions, both for the high wind and low wind conditions. The total expected system cost is the sum of the DA system cost and the expected system cost in real-time dependent on the probability of the scenario. The expected operational cost for each of the sectors is calculated only by taking units and its costs from that sector from Eq. (1). Load shedding and wind spillage costs are calculated based on the sum of the load shedding and wind spillage value respectively in each scenario multiplied with the corresponding probability of the scenario.

Table 2 Comparison of operational cost and wind power curtailment with different flexibility

\begin{tabular}{|c|c|c|c|c|c|c|c|c|c|}
\hline \multirow{2}{*}{$\begin{array}{l}\text { Wind } \\
\text { power } \\
\text { level }\end{array}$} & \multirow[t]{2}{*}{ Cases } & \multirow{2}{*}{$\begin{array}{l}\text { System } \\
\text { with } \\
\text { different } \\
\text { flexibility }\end{array}$} & \multirow{2}{*}{$\begin{array}{l}\text { Wind } \\
\text { power } \\
\text { curtailment } \\
\text { rate }(\%)\end{array}$} & \multirow{2}{*}{$\begin{array}{l}\text { Wind } \\
\text { spillage } \\
\text { cost }(\$)\end{array}$} & \multirow{2}{*}{$\begin{array}{l}\text { Load } \\
\text { shedding cost } \\
(\$)\end{array}$} & \multicolumn{4}{|c|}{ Expected operational costs } \\
\hline & & & & & & Total $(\$)$ & EPS (\$) & DHS (\$) & NGS (\$) \\
\hline \multirow[t]{3}{*}{ High } & Case 1.1 & IES & 0 & 0 & 276.02 & 435.44 & 307.51 & 37.10 & 90.84 \\
\hline & Case 1.2 & EPS-DHS & 35.6 & 208.65 & 362.17 & 637.02 & 599.32 & 37.70 & - \\
\hline & Case 1.3 & EPS-NGS & 0 & 0 & 352.33 & 473.81 & 383.60 & - & 90.22 \\
\hline \multirow[t]{3}{*}{ Low } & Case 2.1 & IES & 0 & 0 & 1650.97 & 1815.38 & 1682.65 & 37.51 & 95.22 \\
\hline & Case 2.2 & EPS-DHS & 24 & 77.97 & 1857.79 & 2001.73 & 1964.31 & 37.42 & - \\
\hline & Case 2.3 & EPS-NGS & 0 & 0 & 1855.46 & 1981.18 & 1886.86 & - & 94.32 \\
\hline
\end{tabular}

As can be seen from Table 2, in Case 1.1 and Case 2.1, the IES has the smallest operational cost and minimum wind power curtailment with multi-energy system integration. This is the result of acquiring the largest flexibility by combining the EPS, DHS and NGS. High wind curtailment, and consequently costs, can be observed as the highest in Case 1.2 and Case 2.2. In Case 1.3 and Case 2.3, wind spillage is not present, as $\mathrm{P} 2 \mathrm{G}$ is accessible. Compared to the other cases, two reasons are behind the high wind spillage in Case 1.2 and Case 2.2. NGS system with the flexibility provided by $\mathrm{P} 2 \mathrm{G}$ is not available. Further, in the 
DHS, the flexibility by the CHP is limited. The comparison cases show that NGS is the main reason for reducing wind power curtailment, which can provide more flexibility than the DHS. Due to the limited flexibility of the CHP unit, the load shedding is higher in Case 1.2 and Case 1.3, and Case 2.2 and Case 2.3. The coupling in the multi-energy system results in increased flexibility of the entire IES.

P2G and gas storage are the main flexibility sources in the NGS. In contrast, the heat storage is the main flexibility sources in the DHS. In order to analyze the influence of the flexibility sources on the economic efficiency and wind power utilization, Table 3 provides the comparison of including and excluding the flexibility sources.

Table 3 IES costs and wind power curtailment during high and low wind power forecasts

\begin{tabular}{clcc}
\hline $\begin{array}{c}\text { Forecasted } \\
\text { wind power }\end{array}$ & System & $\begin{array}{c}\text { Total expected operational } \\
\text { cost [\$] }\end{array}$ & $\begin{array}{c}\text { Wind power curtailment rate } \\
{[\%]}\end{array}$ \\
\hline \multirow{2}{*}{ High } & IES with heat and gas storage & 435.439 & 0 \\
\cline { 2 - 4 } & IES without storages and P2G & 848.411 & 39.8 \\
\hline \multirow{2}{*}{ Low } & IES with heat and gas storage & 1815.383 & 0 \\
\cline { 2 - 4 } & IES without storages and P2G & 2091.724 & 28.8 \\
\hline
\end{tabular}

The flexibility is increased and the operational costs are reduced by integrating storage and $\mathrm{P} 2 \mathrm{G}$ units in the IES, as revealed in Table 3. Wind power curtailment cost equals to zero as the excess electricity is converted to the gas and used in the NGS. There is an increase in wind spillage due to the unavailability of energy storage and P2G units in both days. Moreover, the additional cost of load shedding is accounted for in the low wind forecast day. To conclude, without the energy storage and P2G units, the flexibility of the IES is decreased and the total expected system cost is higher.

\subsection{Evaluation of the impact of temporal-correlated scenario set}

In order to verify the effectiveness of the temporal-correlated scenario set, the Latin hypercube sampling (LHS) is used for comparison. The LHS neglects the temporal correlation. Fig. 6 shows the reduced scenarios with the proposed method in Section 3 and the LHS method. The scheduling results with different scenario sets are compared in Table 4.
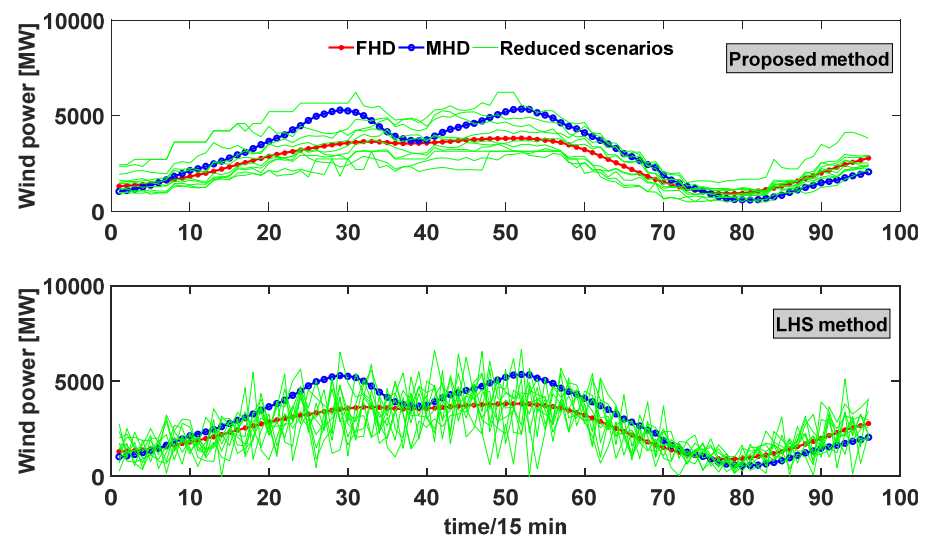

Fig. 6. Measured, forecasted and, reduced scenarios by LHD and proposed method in high wind DA forecast day

Table 4 Scheduling results of IES with LHS scenario set and the temporal-correlated scenario set

\begin{tabular}{ccc}
\hline Scenario generation method for IES & $\begin{array}{c}\text { Total expected system operational } \\
\text { cost }[\mathbf{\$}]\end{array}$ & $\begin{array}{c}\text { Wind power curtailment/Total wind } \\
\text { generation }\end{array}$ \\
\hline Latin hypercube sampling & 371.771 & 0 \\
\hline
\end{tabular}


As can be seen from Table 4, the total expected system cost is lower using the LHS method compared to the proposed method. However, a question arises of how the scenarios fit the actual measured values. It can be observed from Fig. 6 that temporal correlation is not included in the LHS method. Hence, the reduced scenarios are fluctuating. In the proposed method, with the temporal correlation considered, the reduced scenarios follow the actual values. The needed reserve capacity is decided by the scenarios and, as seen from Fig. 6, the LHS is not able to cover the measured values at some periods.

To evaluate the impact of the temporal-correlated scenarios and verify the proposed method, the out-ofsample-error (OSE) is calculated for both the LHS and the proposed method. The OSE is calculated as the root mean square error between each of the generated scenarios and actual MHD value that day and, the average of all the scenarios. The comparison of high and low wind power forecast days is performed. The calculated OSE are shown in Fig. 7. When it comes to high wind days, the proposed method has almost a constant OSE value, while the one with the LHS method is varying depending on the NoS. In the low wind day, the proposed method has even a lower value of the OSE for all NoS considered. However, the LHS method is constant after a certain NoS. The NoS of 100 is necessary to obtain the OSE value similar to the proposed method. Due to the high computational burden of DA scheduling with a large number of scenarios, the LHS method cannot be used because a constant value of the OSE cannot be obtained for all the NoS.

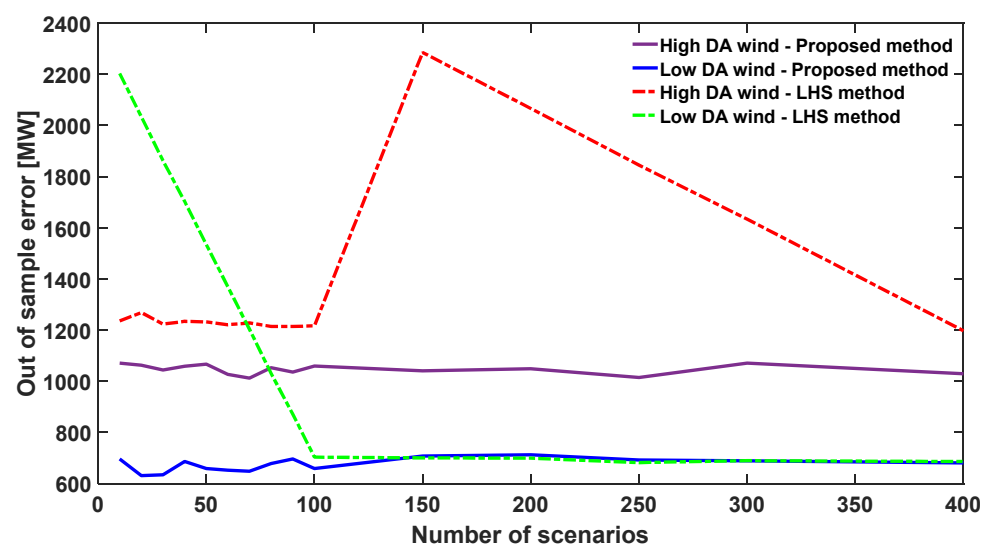

Fig. 7. Out-of-sample-error for LHS method and proposed method for high and low forecasted wind power

As mentioned, the increase in the NoS is causing the computational burden. Therefore, an evaluation of the impact of the NoS on the computational burden is presented in Fig. 8. By changing the NoS for the test system, the CPU time increases. It is expected the CPU time will further increase by increasing the NoS. Furthermore, the total expected system cost is increased as additional scenarios are introduced in the stochastic DA scheduling. It can be observed that, for the high wind power forecast day, the total expected system cost is lower compared to the low wind power forecast due to the high output of the wind power. However, the total expected system operational costs saturate after the NoS equals to 50. 


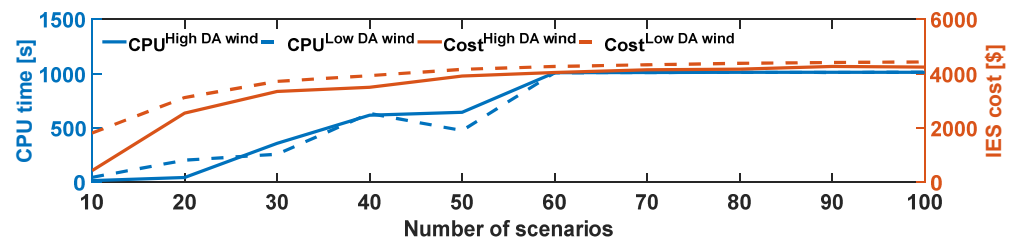

Fig. 8. CPU and IES cost for high and low wind power forecast days for different number of reduced scenarios

The stochastic scheduling approach leads to a lower imbalance in RT compared to the deterministic approach. The two-stage stochastic approach is verified through the value of the stochastic solution obtained for different forecasts and different NoS. Moreover, the expected system cost is lower and reserves are optimized. The two-stage stochastic programming approach shows the minimum operational costs compared to the deterministic one. It has been shown that the NoS required in order to have higher benefits compared to the deterministic approach is not high and can be from 10 to 30 while obtaining lower CPU time. NoS from 40 to 70 requires higher CPU time, and the benefits in terms of VSS are comparable to NoS of lower values.

The proposed SG method is compared to the LHS in Fig. 7. The overall results and comparison are shown in Table 5. The results show that the LHS has almost double the OSE parameters as well as fluctuations by considering the minimum and maximum values of the OSE. The LHS method is not representing realistic scenarios for wind power output.

Table 5. Mean, standard deviation, maximum and minimum of OSE and saturating point of NoS

\begin{tabular}{|c|c|c|c|c|c|c|}
\hline Day & SG method & $\mu_{\text {OSE }}$ (MW) & бOSE (MW) & $\overline{\text { OSE }}(\mathrm{MW})$ & OSE (MW) & Saturating NoS \\
\hline \multirow{2}{*}{$\begin{array}{l}\text { High forecasted } \\
\text { wind power }\end{array}$} & LHS & 1420.84 & 359.66 & 2285.30 & 1196.90 & $>400$ \\
\hline & Proposed method & 1046.15 & 19.34 & 1070.60 & 1011.90 & $>10$ \\
\hline \multirow{2}{*}{$\begin{array}{l}\text { Low forecasted } \\
\text { wind power }\end{array}$} & LHS & 1197.90 & 548.55 & 2203.20 & 681.70 & $>100$ \\
\hline & Proposed method & 674.54 & 25.85 & 712.51 & 630.78 & $>10$ \\
\hline
\end{tabular}

\subsection{Discussion, limitations and application of the proposed method}

The simulation results tested on the small-scale test case system show that both the economic efficiency and wind power utilization have been improved due to flexibility provided by storage devices and P2G units, and an improved and more reliable scenario set. The integration of different energy sectors combining storages and $\mathrm{P} 2 \mathrm{G}$ is proven as the most effective. The benefits of using the proposed method for SG have been shown to perform better than LHS. The proposed method considers the temporal correlation resulting in efficient and cost-effective scheduling of reserves.

Compared to the deterministic DA scheduling, the proposed stochastic DA scheduling leads to lower system costs and imbalance in the RT by considering a number of possible outcomes in the future. However, in order to present all scenarios with the corresponding probability of occurrence, there is a large number of scenarios of possible future states to be included in the optimization problem. Moreover, a large NoS leads to a high computational burden. However, by considering SR, computational burden decreases at the cost of excluding realistically possible outcomes. Therefore, a balance between NoS and computational burden must be considered. On the other hand, a decomposition technique can be implemented for a large number of scenarios resulting in the reduced computational burden compared to the proposed method with a large number of scenarios.

The proposed method is suitable and can be applied when historical data is available. Further on, the covariance matrix structure can be redesigned considering wind spatial correlation and compared to the 
proposed method. Other uncertainties such as load have not been included in this work yet. Furthermore, coordination and co-optimization of EPS, NGS and DHS can be considered a benchmark and extensive work should be done before being applied in the real-world. However, the scheduling is multi-period considering 24 hours ahead, and hence, the technique is promising for a real-world DA scheduling.

\section{Conclusion and improvements}

A two-stage stochastic day-ahead scheduling scheme is proposed for the IES considering synergy of energy sectors and wind power uncertainty. The first stage is representing a scheduling day-ahead market, while the second is accommodating the wind power through reserves. Future realizations of wind power are generated using a scenario generation technique based on historical observations of measured wind power. Due to the high computational burden of a large number of generated scenarios, a backward scenario reduction method is used.

By coordination and synergy of different energy sectors in the IES, a number of beneficial results are obtained. Excess electricity can be converted to the gas using the power to gas unit. Moreover, wind curtailment is reduced and there is a notable decrease in energy costs. Further on, from the economic perspective, with coordination and dispatching of the energy and reserves in the day-ahead market, the system operation costs are minimized. The flexibility is increased by considering energy storage and linking units. Hence, the efficiency and flexibility are improved by using the proposed two-stage stochastic DA scheduling scheme. Moreover, the scenario generation and reduction methods are verified by using a number of different scenarios. Hence, the scenario set generated by the proposed method is providing a more reliable and economical solution. The temporal correlation is included in the proposed method resulting in efficient and cost-effective scheduling of reserves. The following key findings are summarized as follows.

- Integration of electric power system, natural gas and district heating system with linking components such as power-to-gas and storages reduces the wind curtailment and increases system flexibility

- The system operation cost is reduced due to the simultaneous dispatch of energy and reserves.

- The proposed scenario generation algorithm taking into account the temporal correlation of wind power provides a more reliable input for the scheme.

With the current research, data-driven methods based on the measured data are gaining a lot of interest. In the future, the wind spatial correlation can be considered. Moreover, it can be interesting to include other uncertainties in this work. In addition, an increase in flexibility can be accomplished by considering demand response and battery storage.

\section{Acknowledgment}

The work was supported by the EUD Programme through the 'Coordinated Operation of Integrated Energy Systems (CORE)' project under the grant 64017-0005. The authors wish to thank Daniel Müller from Center for Electric Power and Energy (CEE) at DTU for his valuable suggestions. 


\section{Appendix A}

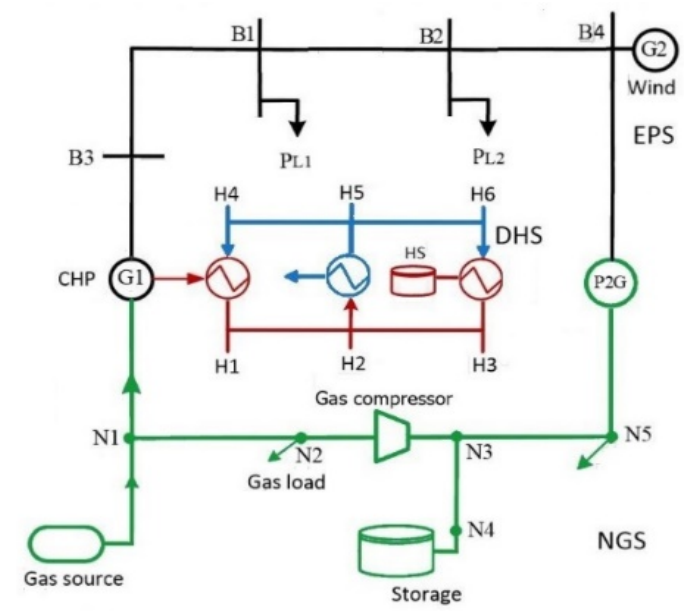

Fig. A. 1. Test case system of IES

Table A. 1. Load profiles for electric, heat and gas demand

\begin{tabular}{c|ccccc} 
TIME & PL1 & PL2 & H25 & N2 & N5 \\
\hline T1 & 0,115 & 0,077 & 0,1991 & 0,09 & 0,07 \\
T2 & 0,111 & 0,074 & 0,1922 & 0,09 & 0,07 \\
T3 & 0,11 & 0,073 & 0,1882 & 0,09 & 0,07 \\
T4 & 0,11 & 0,073 & 0,1867 & 0,09 & 0,07 \\
T5 & 0,113 & 0,075 & 0,1914 & 0,09 & 0,07 \\
T6 & 0,123 & 0,082 & 0,2082 & 0,09 & 0,07 \\
T7 & 0,15 & 0,1 & 0,2546 & 0,1 & 0,08 \\
T8 & 0,18 & 0,12 & 0,3044 & 0,1 & 0,08 \\
T9 & 0,19 & 0,126 & 0,3185 & 0,1 & 0,08 \\
T10 & 0,187 & 0,124 & 0,3108 & 0,1 & 0,08 \\
T11 & 0,19 & 0,127 & 0,3096 & 0,1 & 0,08 \\
T12 & 0,19 & 0,126 & 0,3057 & 0,1 & 0,08 \\
T13 & 0,186 & 0,124 & 0,297 & 0,1 & 0,08 \\
T14 & 0,187 & 0,124 & 0,2977 & 0,1 & 0,08 \\
T15 & 0,184 & 0,123 & 0,2934 & 0,1 & 0,08 \\
T16 & 0,18 & 0,12 & 0,2898 & 0,1 & 0,08 \\
T17 & 0,186 & 0,124 & 0,3035 & 0,1 & 0,08 \\
T18 & 0,197 & 0,131 & 0,3266 & 0,1 & 0,08 \\
T19 & 0,187 & 0,124 & 0,3107 & 0,1 & 0,08 \\
T20 & 0,175 & 0,116 & 0,2908 & 0,1 & 0,08 \\
T21 & 0,162 & 0,108 & 0,2713 & 0,09 & 0,08 \\
T22 & 0,151 & 0,1 & 0,256 & 0,09 & 0,07 \\
T23 & 0,139 & 0,092 & 0,2369 & 0,09 & 0,07 \\
T24 & 0,126 & 0,084 & 0,2203 & 0,09 & 0,07 \\
& & & & & \\
& & & & &
\end{tabular}

Table A. 2. Operation costs for units of IES

\begin{tabular}{cc|cc}
\hline PARAMETER & COST $(\$ / \mathrm{MWH})$ & PARAMETER & COST (\$/MWH) \\
\hline$C_{j}^{\mathrm{CHP}, \mathrm{P}}$ & $\mathbf{1 3}$ & $C_{s}^{\mathrm{HST}, \text { out }}$ & $\mathbf{1 6}$ \\
\hline$C_{g}^{\mathrm{GS}}$ & $\mathbf{8}$ & $C_{s}^{\mathrm{GST}, \text { in }}$ & $\mathbf{2}$ \\
\hline$C_{k}^{P 2 G}$ & $\mathbf{2}$ & $C_{s}^{\mathrm{GST}, \text { out }}$ & $\mathbf{1 0}$ \\
\hline$C_{j}^{\mathrm{CHP}, \mathrm{P}, \mathrm{UR}}$ & $\mathbf{1 4 , 3}$ & $C_{k}^{\mathrm{P} 2 \mathrm{G}, \mathrm{DR}}$ & $\mathbf{1 , 8}$ \\
\hline$C_{j}^{\mathrm{CHP}, \mathrm{P}, \mathrm{DR}}$ & $\mathbf{1 1 , 7}$ & $C_{k}^{\mathrm{P} 2 \mathrm{G}, \mathrm{UR}}$ & $\mathbf{2 , 2}$ \\
\hline$C_{h}^{C H P, H}$ & $\mathbf{4}$ & $C_{k}^{\text {spill }}$ & $\mathbf{1 0 0}$ \\
\hline$C_{s}^{\mathrm{HST}, \text { in }}$ & $\mathbf{2}$ & $C_{d}^{V O L L}$ & $\mathbf{1 2 0 0}$ \\
\hline
\end{tabular}


Table A. 3. Parameter values

\begin{tabular}{|c|c|c|c|}
\hline Parameter & Value & Parameter & Value \\
\hline$\lambda_{m n, t}$ & 0,4 & $\left(p_{n, t}^{2}\right)^{\text {reference }}$ & 1 \\
\hline$\eta^{\mathrm{GC}}$ & 0,85 & $P_{j, t}^{C H P, \min }$ & 0 \\
\hline$\eta_{j}^{\mathrm{e}}$ & 0,3 & $P_{j, t}^{C H P, \max }$ & 1 \\
\hline$\eta_{j}^{h}$ & 0,9 & $R_{j, t}^{\mathrm{CHP}, \mathrm{U}, \max }$ & 0,2 \\
\hline$\eta_{k}^{\mathrm{P} 2 \mathrm{G}}$ & 0,5 & $R_{j, t}^{\mathrm{CHP}, \mathrm{D}, \max }$ & 0,2 \\
\hline$\tau^{a}$ & 10 & $R_{k, \omega, t}^{P 2 G, U, \max }$ & 0,5 \\
\hline$\tau_{m n, t}^{\mathrm{in} / \mathrm{out} \text { min }}$ & 30 & $R_{k, \omega, t}^{P 2 G, D, \min }$ & 0,5 \\
\hline$\tau_{m n, t}^{\text {in/out,max }}$ & 80 & $Q_{g}^{\mathrm{GS}, \min }$ & 0 \\
\hline$c_{k}$ & 1,3 & $Q_{g}^{\mathrm{GS}, \max }$ & 7,7 \\
\hline$C R$ & 1,414 & $Q_{k}^{\mathrm{P} 2 \mathrm{G}, \min }$ & 0 \\
\hline$E^{\mathrm{GC}}$ & 0,99 & $Q_{k}^{\mathrm{P} 2 \mathrm{G}, \max }$ & 0,2 \\
\hline$H_{j}^{C H P, \min }$ & 0 & $Q_{s}^{\mathrm{ST}, \text { in/out,min }}$ & 0 \\
\hline$H_{j}^{C H P, \max }$ & 1 & $Q_{s}^{\mathrm{ST}, \text { in/out,max }}$ & 0,1 \\
\hline$H_{h}^{H S, \text { in } / o u t, \min }$ & 0 & $R L D_{j}^{\mathrm{CHP}}$ & $10 \%(0,1)$ \\
\hline$H_{h}^{H S, \text { in } / \text { out }, \max }$ & 0,1 & $R L U_{j}^{\mathrm{CHP}}$ & $10 \%(0,1)$ \\
\hline$H S_{h}{ }^{0}$ & 0,5 & $S_{n m}^{\max }$ & 5 \\
\hline$H S_{h}^{\min }$ & 0,1 & $P_{\text {base }}$ & $1 \mathrm{MW}$ \\
\hline$H S_{h}^{\max }$ & 0,9 & $S T_{s}^{0}$ & 0,5 \\
\hline$K^{\mathrm{GC}}$ & 0,0854 & $S T_{s}^{\min }$ & 0,1 \\
\hline$L_{m n}\left(L_{12}, L_{23}, L_{65}, L_{54}\right)$ & $400,300,200,300$ & $S T_{s}^{\max }$ & 0,9 \\
\hline$m_{m n, t}^{\min }$ & 1 & $T_{s}$ & 530 \\
\hline$m_{m n, t}^{\max }$ & 3 & $Z_{\mathrm{a}}$ & 0,95 \\
\hline$\left(p_{n, t}^{2}\right)^{\min }$ & 0,25 & $W_{f, t}^{\max }$ & 0,6 \\
\hline$\left(p_{n, t}^{2}\right)^{\max }$ & 4 & $Z_{n m}\left(Z_{12}, Z_{23}, Z_{34}, Z_{35}\right)$ & $\begin{array}{l}0,0280 ; 0,0373 ; \\
0.0186 ; 0.0202\end{array}$ \\
\hline
\end{tabular}




\section{References}

[1] State of energy, "Denmark set new wind record in 2017," [Online]. Available: https://stateofgreen.com/en/partners/stateof-green/news/denmark-set-new-wind-record-in-2017/.

[2] Zeng Q, Zhang B, Fang J, Chen Z. , "A bi-level programming for multistage co-expansion planning of the integrated gas and electricity system," Applied Energy, vol. 200, pp. 192-203, 2017.

[3] Lund H, Duic N, Østergaard P A, Mathiesen B V, "Future district heating systems and technologies: On the role of smart energy systems and 4th generation district heating," Energy, vol. 165, no. Part A, pp. 614 - 619, 2018

[4] Frank S, Rebennack S, "An introduction to optimal power flow: Theory, formulation, and examples," IIE Transactions, vol. 48, no. 12, pp. 1172-1197, 2016.

[5] Lund H, Østergaard P A, Chang M, Werner S, Svendsen S, Sorknæs P, Thorsen J E, Hvelplund F, Mortensen B O G, Mathiesen B V, Bojesen C, Duic N, Zhang X, Möller B, "The status of 4th generation district heating: Research and results," Energy, vol. 164, pp. 147-159, December 2018

[6] Leitner B, Widl E, Gawlik W, Hofmann R, "A method for technical assessment of power-to-heat use cases to couple local district heating and electrical distribution grids," Energy, vol. 182, pp. 729-738, 2019.

[7] Li J, Fang J, Zeng Q, Chen Z, "Optimal operation of the integrated electrical and heating systems to accommodate the intermittent renewable sources," Journal of Applied Energy, vol. 167, pp. 244-254, 2016.

[8] Liu X, Wua J, Jenkins N, Bagdanavicius A, "Combined analysis of electricity and heat networks," Journal of Applied Energy, vol. 162, pp. 1238-1250, 2016.

[9] Pan Z, Guo Q, Sun H. "Interactions of district electricity and heating systems considering time-scale characteristics based on quasi-steady multi-energy flow," Appl Energy Apr. 2016; 167:230-43.

[10] Pan Z, Guo Q, Sun H. "Feasible region method based integrated heat and electricity dispatch considering building thermal inertia," Appl Energy Apr. 2017; 192:395-407.

[11] Seungwon A, Li Q, Gedra T W, "Natural gas and electricity optimal power flow," in 2003 IEEE PES Transmission and Distribution Conference and Exposition, 2003.

[12] Shahab B., and Sheikhi A., "From demand response in smart grid toward integrated demand response in smart energy hub," IEEE Transactions on Smart Grid 7.2 (2015): 650-658.

[13] Zeng Q, Fang J, Li J, Chen Z. , "Steady-state analysis of the integrated natural gas and electric power system with bidirectional energy conversion," Applied Energy, vol. 184, pp. 1483-1492, 2016.

[14] Fang J, Zeng Q, Ai X, Chen Z, and Wen J, "Dynamic Optimal Energy Flow in the Integrated Natural Gas and Electrical Power Systems, " IEEE Trans. Sustain. Energy," vol. 99, pp. 188 - 198, 2017.

[15] Yang Z, Gao C, Zhang J, "The Interaction of Gas and Electricity hybrid Energy Internet," in IEEE Conference on Energy Internet and Energy System Integration (EI2), 2017.

[16] ForskEL, HIGHE (No. 12220), "Final report on Harmonized Integration of Gas, District Heating and Electric Systems," Aalborg University, Aalborg, Denmark, 2017.

[17] H Lund, P. A. Østergaard, D. Connolly, B. V. Mathiesen, "Smart energy and smart energy systems," Energy, p. http://dx.doi.org/10.1016/j.energy.2017.05.123, 2017.

[18] Sun H, Guo Q, Zhang B, Wenchuan Wu, Wang B, Shen X, Wang J, Integrated Energy Management System: Concept, Design, and Demonstration in China, IEEE Electrification Magazine, 2018, 6(2): 42-50.

[19] Zeng Q, Fang J, Zhang B, and Chen Z, "The coordinated operation of electricity, gas and district heating systems," Applied Energy Symposium and Forum, Renewable Energy Integration with Mini/Microgrids, REM 2017, 2017.

[20] Zeng Q, Conejo A J, Chen Z, Fang J, "A Two-stage Stochastic Programming Approach for Operating Multi-energy Systems," in First IEEE Conference on Energy Internet and Energy System Integration, 2017.

[21] Schulzea T, McKinnon K, "The value of stochastic programming in day-ahead and intra-day generation unit commitment," Energy, vol. 101, pp. 592-605, 2016.

[22] Lei M, Zhang J, Dong X, Ye J J, "Modeling the bids of wind power producers in the day-ahead market with stochastic market clearing," Sustainable Energy Technologies and Assessments, vol. 16, pp. 151 - 161, 2016.

[23] Marneris I G, Biskas P N and Bakirtzis A G, "Stochastic and Deterministic Unit Commitment Considering Uncertainty and Variability Reserves for High Renewable Integration," Energies, MDPI, Open Access Journal, vol. 10, no. 1, pp. 1 $-25,2017$

[24] Gomes I L R, Pousinho H M I, Melício R, Mendes V M F, "Stochastic coordination of joint wind and photovoltaic systems with energy storage in day-ahead market," Energy, Elsevier, vol. 124, pp. 310-320, 2017.

[25] Shahab B, and Amini M, "A Decentralized Trading Algorithm for an Electricity Market with Generation Uncertainty," Applied Energy 218 (2018): 520-532.

[26] Zhang J, Fuller J D, and Elhedhli S, "A Stochastic Programming Model for a Day-Ahead Electricity Market With RealTime Reserve Shortage Pricing," IEEE Transactions on Power Systems, vol. 25, no. 2, pp. 703 - 713, 2010.

[27] Liu P., "A Dissertation, Stochastic and robust optimal operation of energy-efficient building with combined heat and power systems," Faculty of Mississippi State University, Mississippi , 2014.

[28] Rabiee A and Soroudi A, "Stochastic Multiperiod OPF Model of power Systmes With HVDC-Connected Intermittent Wind Power Generation," IEEE Transactions on Power Delivery, vol. 29, no. 1, pp. 336-344, 2014.

[29] Atwa Y M and Saadany E F El, "Probabilistic approach for optimal allocation of wind-based distributed geneartion in distribution systems," IET Renewable Power Generation, vol. 5, no. 1, pp. 79-88, 2011 
[30] Shi L, Wang C, Yao L, Ni Y, Bazargan M, "Optimal power Flow Solution Incorporating Wind Power," IEEE Systems Journal, vol. 6, no. 2, pp. 233-241, 2012.

[31] Bornapour M, Hooshmand R A, Khodabakhshian A, Parastegari M, "Optimal coordinated scheduling of combined heat and power fuel cell, wind, and photovoltaic units in micro grids considering uncertanties," Energy, vol. 117, pp. 176$189,2016$.

[32] Wu L, Shahidehpour M, T. Li, "Stochastic Security-Constrained unit Commitment," IEEE Transactions on Power Systems, vol. 22, no. 2, pp. 800-811, 2007.

[33] Bornapor M, Hooshmand R A, "An efficient scenario-based stochastic programming for optimal planning of combined heat, power, and hydrogen production of molten carbonate fuel cell power plants," Energy, vol. 83, pp. 734-748, 2015

[34] Yao L, Wang X, Ding T, Wang Y, Wu X, Liu J, "Stochastic Day-ahed Scheduling of Integrated Energy Distribution Network with Identifying Redundant Gas network Constraints," IEEE Transactions on Smart Grid, , vol. 10, no. 4, pp. 4309-4322, 2019.

[35] Morales J M, Pineda S, Conejo A J, Carrion M, "Scenario Reduction for Future Market Trading in Electricity Markets," IEEE Transactions on Power Systems, vol. 24, no. 2, pp. 878-888, 2009.

[36] Yıldız C, Tekin M, Gani A, Keçecioğlu Ö. F, Açıkgöz H and Şekkeli M, "A Day-Ahead Wind Power Scenario Generation, Reduction, and Quality Test Tool," Sustainability, vol. 9, no. 5, pp. 1-15, 2017.

[37] Ma X-Y., Sun Y-Z., Fang H-L., "Scenario Generation of Wind Power based on Statistical Uncertanty and Variablity," IEEE Transactions on Sustainable Energy, vol. 4, no. 4, pp. 894-904, 2013.

[38] Zhang M., Ai X., Fang J., Yao W., Zuo W., Chen Z., Wen J., "A systematic approach for the joint dispatch of energy and reserve incorporating demand response," Applied Energy, vol. 230, pp. 1279-1291, 2018.

[39] Danish Energy Agency, "Regulation and planning of district heating in Denmark," June 2017. [Online]. Available: https://ens.dk/sites/ens.dk/files/Globalcooperation/regulation_and_planning_of_district heating_in_denmark.pdf. [Accessed 0412 2019].

[40] Energinet, "Security of gas supply 2018," Energinet, 2018.

[41] Yalmip, "Unit commitment," [Online]. Available: https://yalmip.github.io/example/unitcommitment/. [Accessed 2502 2019].

[42] GAMS, "GAMS Documentation: Solver Manual CPLEX12," May 2018. [Online]. Available: https://www.gams.com/latest/docs/S_CPLEX.html. [Accessed 0512 2019].

[43] Tomasgard A., Rømo F., Fodstad M., and Midthun K., "Optimization models for the natural gas value chain," Norwegian University of Science and Technology, SINTEF .

[44] L. Bai, "Doctoral Dissertations :'Co-Optimization of Gas-Electricity Integrated'," University of Tennessee, Knoxville,, 2017

[45] Ye J and Yuan R, "Integrated Natural Gas, Heat, and Power Dispatch Considering Wind Power and Power-to-Gas," Sustainability, vol. 9, no. 4, p. 602, 2017.

[46] Li G, Zhang R, Jiang T, H. Chen, L. Bai, H. Cui, X. Li, "Optimal dispatch strategy for integrated energy systems with CCHP and wind power," Applied Energy, vol. 192, pp. 408 - 419, 2017.

[47] Correa-Posada C M and Sánchez-Martín P, "Integrated Power and Natural Gas Model for Energy Adequacy in ShortTerm Operation," IEEE TRANSACTIONS ON POWER SYSTEMS, vol. 30, no. 6, 2015

[48] Sirvent M, N, Kanelakis, B. Geisler, P. Biskas, "Linearized model for optimization of coupled electricity and natural gas systems," J. Mod. Power Syst. Clean Energy, vol. 5, no. 3, pp. 364-374, 2017.

[49] C M. Correa-Posada and P. Sánchez-Martín, "Gas Network Optimization: A comparison of Piecewise Linear Models," Chemical Engineering Science, 2014.

[50] Antonio J. Conejo, Miguel Carrión, Juan M. Morales, Decision Making Under Uncertainty in Electricity Markets, New York: Springer, 2010.

[51] Energinet, "Electricity: Energy data," [Online].

[52] Mitridati L and Pinson P, "Optimal Coupling of Heat and Electricity Systems: A Stochastic Hierarchical Approach," in 2016 International Conference on Probabilistic Methods Applied to Power Systems (PMAPS), Beijing, China, 2016.

[53] Ordoudis C, Delikaraoglou S, Pinson P, \& Kazempour J, "Exploiting Flexibility in Coupled Electricity and Natural Gas Markets: A Price-Based Approach," in Proceedings of IEEE PES PowerTech Conference 2017, IEEE. DOI: 10.1109/PTC.2017.7981047, 2017.

[54] Tennet, "Day ahead generation forecast \& actuals wind," 2019. [Online]. Available: Historical data for wind power output used in the scenario generation can be found in .. [Accessed 08 2019].

[55] Morales J M, Conejo A J, Madsen H, Pinson P, Zugno M, Integrating Renewables in Electricity Markets, New York: Springer, 2014. 